\title{
INTERNATIONAL PATENTING STRATEGIES WITH HETEROGENEOUS FIRMS
}

\author{
by \\ Nikolas J. Zolas* \\ U.S. Census Bureau
}

\section{CES 14-28 August, 2014}

The research program of the Center for Economic Studies (CES) produces a wide range of economic analyses to improve the statistical programs of the U.S. Census Bureau. Many of these analyses take the form of CES research papers. The papers have not undergone the review accorded Census Bureau publications and no endorsement should be inferred. Any opinions and conclusions expressed herein are those of the author(s) and do not necessarily represent the views of the U.S. Census Bureau. All results have been reviewed to ensure that no confidential information is disclosed. Republication in whole or part must be cleared with the authors.

To obtain information about the series, see www.census.gov/ces or contact Fariha Kamal, Editor, Discussion Papers, U.S. Census Bureau, Center for Economic Studies 2K132B, 4600 Silver Hill Road, Washington, DC 20233, CES.Papers.List@census.gov. 


\begin{abstract}
This paper analyzes how firms decide where to patent in a heterogeneous firm model of trade with endogenous rival entry. In the model, innovating firms compete with rival firms on price, where rivals force the innovating firm to reduce markups and lower the innovating firm's probability of obtaining monopolistic profits. Patenting allows the innovating firm to reduce the number of rival firms by increasing their fixed overhead costs, thereby providing higher expected profits and increased markups from reduced competition. Countries with higher states of technology, more competition and better patent protection have a greater proportion of entrants who patent. Industries tend to follow a U-shaped pattern of patenting where industries with high heterogeneity in production and low substitution, along with industries with low heterogeneity in production and high substitution patent more frequently. Using a generalized framework of the model, I estimate market-based measures of country-level patent protection, which when compared with other IP indices, suggests that not enough international patenting is taking place. Finally, I test the predictions of the model using a newly available technology-to-industry concordance on bilateral patent flows and show that firms are increasingly sensitive to foreign IP protection. Countries that choose to maximize their IP protection can increase the number of foreign patents by almost $10 \%$.
\end{abstract}

Keyword: Patents, international trade, heterogeneous rms, endogenous markups, intellectual property, imperfect competition

JEL Classification: F12, F29, O34, L11

\footnotetext{
* I am grateful for all of the assistance provided by Robert Feenstra, Travis Lybbert, Giovanni Peri, Katheryn Russ, Deborah Swenson, Emin Dinlersoz, Farid Toubal, Greg Wright, Andrew McCallum and Anson Soderbery. The views in this paper are those of the author and do not necessarily represent the views or policies of the US Census Bureau. All remaining errors are mine. This paper was previously titled "Firm Locational Patenting Decisions." Contact: nikolas.j.zolas@census.gov
} 


\section{Introduction}

Most worldwide innovation is concentrated in a handful of countries, with the majority of global innovation taking place in the U.S., Japan, China, South Korea and Europe. Countries outside of this group increasingly rely on the international diffusion of new technologies for technological change and productivity growth (Eaton and Kortum (1996a)). These technologies diffuse across international borders through multiple channels, with trade and foreign direct investment (FDI) both playing prominent roles (Eaton and Kortum 1996b; Archaya and Keller 2009; Branstetter 2006). Much work has been done in assessing which national policies have most directly affected the dynamics of technology diffusion with trade policy and intellectual property rights (IPR) receiving considerable attention (Grossman and Helpman 1991; Ethier and Markusen 1996; Branstetter et al. 2006; Keller 2004; Archaya and Keller 2009; Falvey et al. 2006).

In finding ways to narrow the current technological divide and promote international technology diffusion, patents offer a promising solution. Nearly all patentable innovations undergo the patenting process (Dernis et al. (2001)). International patents are often a precondition for collaborative technology transfer. Only after a firm holds a patent right in a country is it likely to actively share proprietary technology either through joint ventures with an already established company, granting licenses for production or relocating production to that country. For example, a rigorous analysis of multinational firms and their affiliates concludes that strengthening patent protection in the affiliate country increases subsequent patent applications, R\&D investment, and technology transfer (Branstetter et al. (2006)). While a developing country can choose to use a patented invention without the authorization of the inventor, many developing countries will struggle to successfully leverage the invention without the interest and cooperation of the patent holder. For such countries, the patenting decision can be an important precursor for the transfer of cutting-edge technology, which can subsequently spark the long-run diffusion of technology and knowledge.

Firms consider many different strategies when it comes to patenting, with two of the most important factors being cost and timing (Livne 2006; Schneiderman 2007). In their survey of U.S. manufacturing firms, Cohen et al. (2000) find that firms patent mainly to prevent imitation and counterfeiting, but also for reasons such as patent blocking, negotiations with other firms, the prevention of lawsuits and competition. The cost of patenting can pile up very quickly, with filing fees, agent fees and translation fees bringing the total application cost to more than $\$ 10,000$ per application in several countries (Source: WIPO). In addition, there are also transaction costs, interaction costs with licensing professionals and knowledge costs of exposing ideas to potential imitators. On the other hand, the benefits of patenting give the firm additional market power, 
allowing them to charge higher markups and higher profits (Horstmann et al. 1985; Owen-Smith and Powell 2001).

Unfortunately, our understanding of how firms decide whether and where to seek patent protection abroad is poor. This paper seeks to remedy this gap in the literature by incorporating a patenting decision component into a heterogeneous firm model of trade (similar to Helpman et al. (2004) (HMY)) with imperfect competition (similar to de Blas and Russ (2011) (DBR)). In the model, innovating firms compete with rival firms on price (Bertrand competition). The number of rivals and their productivities depend on the innovating firm's own productivity so that more productive innovating firms face a greater number of more competitive rivals. This creates greater incentives for them to patent, which acts as a way to reduce the number of rivals by increasing their overhead costs as rivals must now work around the innovation. The benefit of this model is that it manages to maintain the producer-level facts regarding the behavior and composition of exporting firms and multi-nationals in the 'new' new trade theory, while allowing for cross-country and cross-industry differences to determine the flows of international patenting. These cross-country and cross-industry differences play a key role in deciding spacial patenting outcomes.

These spatial patterns of patenting have important implications for development and are the topic of much debate regarding international technology transfer. The role of patent rights figured prominently in the original negotiations of the Trade-Related Aspects of Intellectual Property Rights Agreement (TRIPS) in the Uruguay Round of GATT in 1994. Throughout these negotiations developing countries expressed concern that stronger IPR would only benefit wealthy countries that had already developed strong innovation capacity. Wealthy countries therefore agreed to a provision to provide incentives for firms to transfer technology to developing countries and enable them to build a viable technological base (Article 66.2 of the TRIPS Agreement). Implicit in this provision is the hope that offering stronger patent protection to foreign innovators might increase the flow of patents and thereby speed up the process of technology transfer. Where firms choose to patent is therefore central in this debate.

Looking at the number of international patents since the TRIPS agreement, Figure 1 shows that the number of patents being applied for across multiple jurisdictions has steadily increased between 1994 and 2008, while at the same time, the mean number of jurisdictions per patent has steadily declined. The figure highlights that while more firms are choosing to patent abroad, these same firms are becoming more selective as to which jurisdiction they apply in. 


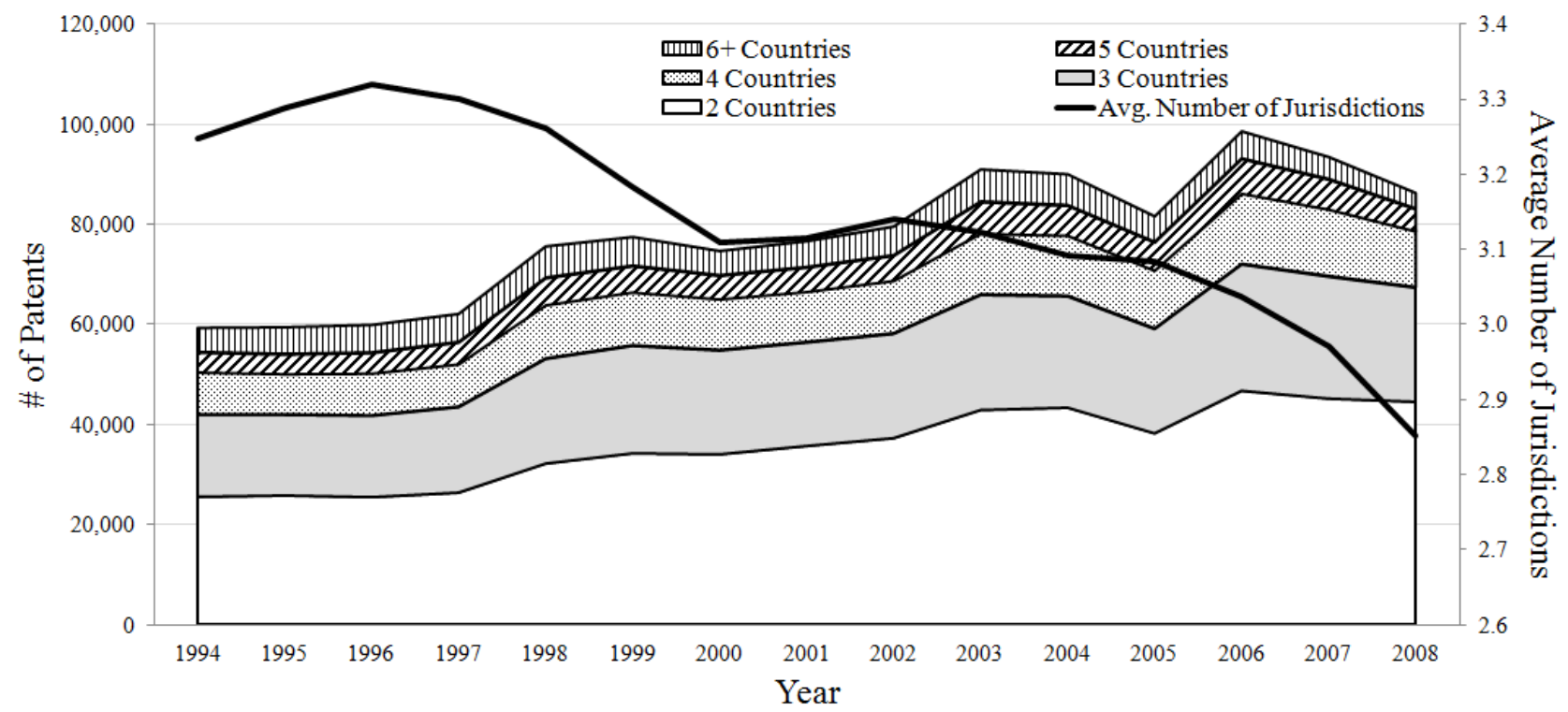

Figure 1: Number of Patents Applied For (and Granted) in Multiple Jurisdictions, 1994-2008

In addition to this selectivity issue, the set of "core" countries that countries choose to apply in has also changed over this time period, with firms focusing less on Europe and shifting their patents towards Asia, and specifically China. Figure 2 plots the probability of patenting in 16 jurisdictions based on the size (i.e. number of countries) of the patent. 

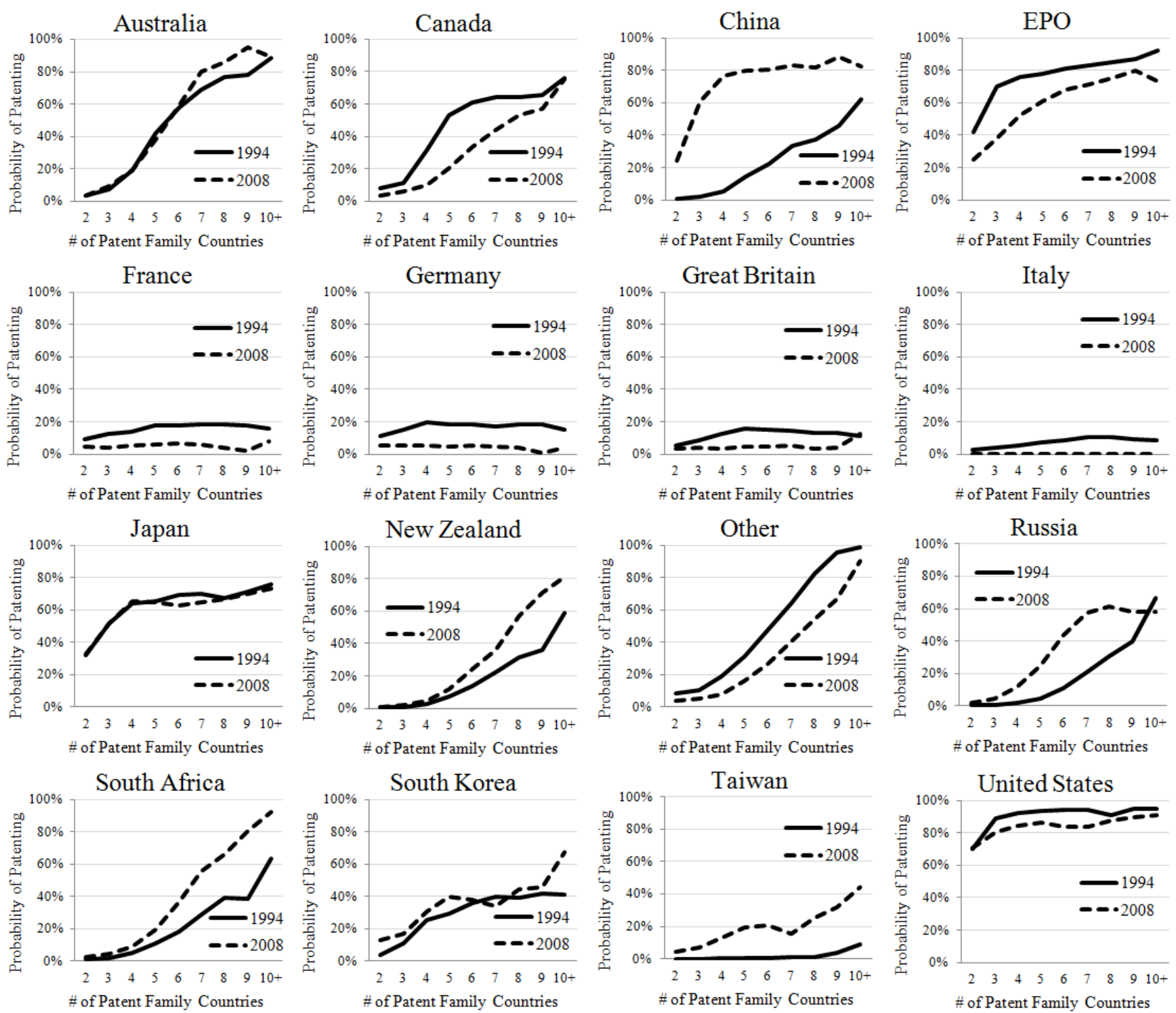

Figure 2: Probability of Patenting in Given Jurisdiction based on Size of Patent Family, 1994-2008

Together, these two figures point to a fairly large shift in international patenting strategies. This model begins to address some of the questions posed by this shift by providing a specific framework to analyze market-based outcomes of international patenting patterns. Using a database of patent families (the set of patent applications in different countries that relate to a single parent invention) compiled by the World Intellectual Property Organization (WIPO) and the EPO, the model can back out market-based measures of country patent protection (IPR). When compared to previous measures of IPR from Park (2008), initial evidence suggests that not enough foreign patenting is taking place. Using these new measures of IPR, the predictions of the model are tested by looking at the determinants of bilateral patent flows to 28 destination 
countries between the years 1996 to 2005. The data confirms several predictions of the model and can explain cross-country variations in patenting to a much higher degree than previous models.

The contributions of this paper to the literature are several. This paper describes a new version of a heterogeneous model of trade by incorporating endogenous entry of rivals. It is most similar in structure to the model described in DBR with the exception that rival entry will be determined by the innovating firm's productive capability. This has important implications on both the number and composition of rivals, as well as markups. In addition to this new framework, this model also includes a patenting decision component that is markedly different from previous models, like Eaton and Kortum (1996b) (EK). EK incorporates patenting into a quality ladders model where the firm decision to patent depends on the hazard rate of imitation and obsolescence of the invention, the patent decision here depends on the number of competitors and probability of imitation. Thus, if there are no rivals (either foreign or domestic), there is no need to patent. Finally, this paper is also the first to obtain market-based measures of patent protection, meaning that it uses actual patent flows to back out the IPR measures. Previous measures of IPR have been constructed using subjective determinants, such as enforcement of IPR, coverage and membership in international agreements. The market-based measures serve as an alternative measure of IPR that focus strictly on what firms consider to be most relevant in deciding whether/where to patent. The next section defines the model and outlines the process to calculate a numerical equilibrium. Section 3 describes the properties of the equilibrium using simulations and parameter estimates. Section 4 describes the empirical portion and constructs market-based measures of IPR using nonlinear least squares (NLLS). This is followed by the conclusion.

\section{Model}

The core elements of the model are based primarily on de Blas and Russ (2011) (DBR), with differences in the composition of rivals and allowing innovating firms to patent.

\subsection{Demand}

Assume that that there are $i=1, \ldots, I$ countries where each country has the ability to produce $k=1, \ldots, K$ different goods or industries. Next, assume only one factor of production, labor $L_{i}$, which is perfectly mobile across industries but not countries and paid wage $w_{i}$. Each good $k$ is comprised of an infinite number of 
varieties, which will be indexed by $\omega \in \Omega$.

In each country, preferences are given by a representative consumer with a two-tier utility function. The upper-tier utility function is Cobb-Douglas where the share of expenditure on varieties from industry $k$ in country $i$ are given by $\alpha_{i}^{k}$ where $0 \leq \alpha_{i}^{k} \leq 1$. The lower-tier utility function is CES with elasticity of substitution $\sigma^{k}$ between varieties. Thus, in any country $i$, the total expenditure on variety $\omega$ of good $k$ will be given by:

$$
x_{i}^{k}(\omega)=\left(\frac{p_{i}^{k}(\omega)}{P_{i}^{k}}\right)^{1-\sigma^{k}} \alpha_{i}^{k} w_{i} L_{i}
$$

where $P_{i}^{k}$ is the CES price index ${ }^{1}$. Given these assumptions, the consumer price index in country $i$ is given by $P_{i}=\prod_{k=1}^{K}\left(p_{i}^{k}\right)^{\alpha_{i}^{k}}$.

\subsection{Production and Innovation}

Labor is the only factor used in production and is assumed to be perfectly mobile across types and goods, but immobile across countries. I denote $z_{i}^{k}(\omega)$ to be the measure of productivity of variety $\omega$ in industry $k$. I assume that there are two types of firms in the world economy: i.) Innovating firms who pay a one-time fixed cost of innovation $I_{i}^{k}$ that allows them to draw their productivity parameter $z$ from an unbounded distribution and ii.) Imitating or rival firms who do not pay an entry fee but are bounded in their productivity draws by the innovating firms' productive capability.

Both types of firms draw their productivity $z_{i}^{k}(\omega)$ from the same distribution type. If we think of innovating firms as repeatedly drawing ideas from a set of existing ideas, then the best (i.e. most efficient) surviving idea takes on a Fréchet (inverted Weibull) distribution $F_{i}^{k}(z)$ with positive support (see Eaton and Kortum (2009), Chapter 4). The Fréchet distribution will be governed by two separate parameters: a country-industry specific technology parameter $T_{i}^{k}$ which will govern the mean of the distribution and an industry specific shape parameter $\theta^{k}>1$ that determines the heterogeneity of efficiency levels. The distribution for the innovating firms is given by

$$
F_{i}^{k}\left(z \mid T_{i}^{k}, \theta^{k}\right)=\operatorname{Pr}\left[z_{i}^{k} \leq z\right]=e^{-T_{i}^{k} z^{-\theta^{k}}}
$$

\footnotetext{
${ }^{1}$ Given by $P_{i}^{k}=\left(\sum_{\omega \prime \in \Omega} p_{i}^{k}(\omega \prime)^{1-\sigma^{k}}\right)^{1 /\left(1-\sigma^{k}\right)}$
} 
A higher $T_{i}^{k}$ implies higher technology and greater productivity on average, while a higher $\theta^{k}$ means lower variability in labor efficiencies so that producers are more homogeneous. In order to guarantee the existence of a well-defined CES price index $P_{j}^{k}$, I assume that the elasticity of substitution $\sigma_{i}^{k}<1+\theta^{k}$.

Next, I drop the superscript $k$ and assume that the following holds for each industry type $k=1, \ldots, K$. Once the innovating firm in country $i$ draws this parameter $z$, they decide whether to pay a per-period fixed cost to enter the market and sell their good in market $j, f_{i j}^{*}$. The innovating firm can choose to either export, paying a per-period fixed cost of $f_{i j}^{X}$, along with iceberg trade costs $d_{i j}$ and the home country wage of $w_{i}{ }^{2}$. Or the firm can relocate abroad, paying a higher per-period fixed cost $f_{i j}^{F}$ and the destination country's wages as in Helpman et al. (2004). For the purposes of this model, it makes no difference which method the firm chooses to sell the good in destination $j$. The outcomes of the model will depend only on the cost function after the firm makes this choice, which is denoted as $c_{i j}^{I}{ }^{3}$.

Given CES demand, the optimal price for the innovating firm will be to charge a CES or monopolistic markup. Without any rivals and with the exception of different productivity distributions, the equilibrium and properties of the equilibrium are similar to the results obtained in Helpman et al. (2004).

\subsection{Production and Imitation}

Assume that for each new variety $\omega$ in each market $j$, the innovating firm faces some number $r_{j}$ of rivals or imitators who compete with the firm on price (Bertrand) as in Eaton and Kortum (2002) (BEJK) and de Blas and Russ (2011) (DBR). Unlike BEJK and DBR however, the number of rivals and possible imitators in each country is endogenously determined by the productivity parameter of the innovating firm ${ }^{4} \mathrm{To}$

\footnotetext{
${ }^{2}$ All trade costs are positive $\left(d_{i j} \geq 1\right)$ and I assume that trade barriers obey the triangle inequality so that $d_{i j} \leq d_{i n} d_{n j}$ for all $i, j$ and $n$

${ }^{3}$ Formally, $c_{i j}^{I}$ is written as
}

$$
c_{i j}^{I}= \begin{cases}\frac{w_{j}}{z_{i}^{I}} & z_{i}^{I} \geq\left[\frac{(\sigma)^{\sigma}}{(\sigma-1)^{\sigma-1}} \frac{f_{i j}^{F}-f_{i j}^{X}}{\alpha_{j} Y_{j}}\left(w_{j}^{1-\sigma}-\left(w_{i} d_{i j}\right)^{1-\sigma}\right)\right]^{\frac{1}{\sigma-1}} P_{j} \\ \frac{w_{i} d_{i j}}{z_{i}^{I}} & \text { Otherwise }\end{cases}
$$

Where $Y_{j}$ is country-level income (equal to $w_{j} L_{j}$ ). Assuming $\left(\frac{w_{j}}{w_{i}}\right)^{\sigma-1} f_{i j}^{F}>d_{i j}^{\sigma-1} f_{i j}^{X}$. The firm will make the choice to either export or commit FDI using the CES/monopolistic markup.

${ }^{4}$ As DBR note, BEJK assumes that the number of rivals for any given product is a random variable determined by a Poisson distribution. This assumption allows the number of rivals to cancel out in the analysis (see Eaton and Kortum (2009), Chapter 4). On the other hand, DBR assume that the number of rivals is determined solely by the free-entry condition, and is therefore 
do this, the rival firms' marginal cost distributions will be bounded by the marginal costs of the innovating firm, so they are never more efficient at producing variety $\omega$ than the firm who invented it. Since the firms compete on price, this implies that the rival firms will never make positive profits unless the innovating firm is forced to exit. However, rivals do not pay a fixed cost of entry or 'innovation cost' and are able to enter and exit at any given time. In other words, they simply act as a 'credible threat' to the innovating firm and as a mechanism to ensure that the innovating firm does not charge a dubious markup.

I denote the rival productivity in country $j$ as $z_{j}^{R}$. Each of the rivals have constant returns to scale and their marginal costs are given by $c_{j}^{R}(\omega)=\frac{w_{j}}{z_{j}^{R}(\omega)}$. The rivals face the same demand functions as their counterparts, so that the profit function is similar to the innovating firm's profit function, with the exception that each rival pays a different per-period fixed overhead cost $f_{j}^{R}$ to enter into the market. Due to this per-period fixed cost, there exists a non-zero cutoff cost parameter $\tilde{c}_{j}^{R}$ that governs whether the rival has the low-cost necessary to compete and serve as a credible threat. This cutoff condition $\tilde{c}_{j}^{R}$ is determined by assuming monopolistic pricing and setting the profit equal to zero so that $\tilde{c}_{j}^{R}$ corresponds to the productivity threshold sufficient to cover the fixed per-period overhead costs.

$$
\tilde{c}_{j}^{R}=\left[\frac{(\sigma)^{\sigma}}{(\sigma-1)^{\sigma-1}} \frac{f_{j}^{R}}{\alpha_{j} Y_{j}}\right]^{\frac{1}{1-\sigma}} P_{j}
$$

Rivals who draw a cost parameter $c \leq c_{j}^{R}$ are permanent entrants and remain as credible threats in the market for as long as the innovating firm competes. Rivals who draw $c>c_{j}^{R}$ can never enter and are therefore not deemed credible. Each rival draws their cost parameters $c$ from a similar shape distribution as the innovating firm (i.e. Fréchet), but their support is truncated by the marginal costs of the innovating firm which will be denoted as $c_{i j}^{I}{ }^{5}$. The CDF of the rivals' cost function in country $j$ is ${ }^{6}$

unaffected by the productivity of the innovating firm. The model here assumes that the number of rivals is determined jointly by the zero-profit condition and innovating firm's productivity.

${ }^{5}$ Note that the definition of $c_{i j}^{I}$ will vary by innovating firm type (exporting or FDI)

${ }^{6}$ Formula for a left-truncated Weibull distribution can be found on pages 134-135 in Rinne (2009). Note that the corresponding productivity CDF for the rivals is given by

$$
F_{j}^{R}\left(z \mid z_{i}^{I}, T_{j}, \theta\right)=e^{-T_{j}\left(z^{-\theta}-\left(\frac{w_{j}}{w_{i} d_{i j}}\right)^{-\theta}\left(z_{i}^{I}\right)^{-\theta}\right)}
$$

for exporting firms and

$$
F_{j}^{R}\left(z \mid z_{i}^{I}, T_{j}, \theta\right)=e^{-T_{j}\left(z^{-\theta}-\left(z_{i}^{I}\right)^{-\theta}\right)}
$$

for FDI firms, where $z_{i}^{I}$ is the productivity parameter of the innovating firm 


$$
G_{j}^{R}\left(c \mid c_{i j}^{I}, T_{j}, \theta\right)=1-e^{-T_{j} w_{j}^{-\theta}\left(c^{\theta}-\left(c_{i j}^{I}\right)^{\theta}\right)}
$$

A depiction of the rival and innovating firms' distributions is given below in Figure 3. In each chart, the leftmost $c$ represents the cost parameter for the innovating firm and shows a left-truncation of the rivals' cost distribution. The rightmost $c$ is the equivalent cost parameter for the cutoff condition for rival entry (given as the inverse of $z_{j}^{R}$, so that the area in between the two lines is the ex-ante probability of successful entry by the rivals in country $j$. The figure depicts three separate charts that are differentiated by the technology levels in the destination country. The state of technology in each country will play an important role in determining both the number of rivals, as well as the efficiency of the rivals. In Figure 3a, the technology for the innovating firm's country is higher than the country of the rival firms. Figure 3a shows that the innovating firm from country $i$ will not only face relatively fewer rivals, but also those rivals have lower average productivity than the innovating firm (since the fat part of the distribution is closer to $c_{j}^{R}$ ). In Figure 3c, the opposite occurs. The country of the rival firms has higher technology and the innovating firm not only faces more competition, but each competitor will have cost parameters that are closer to the innovating firm's cost parameter.

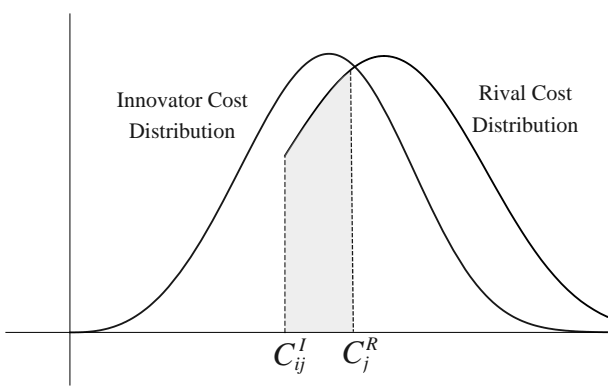

1a. $T_{i}>T_{j}$

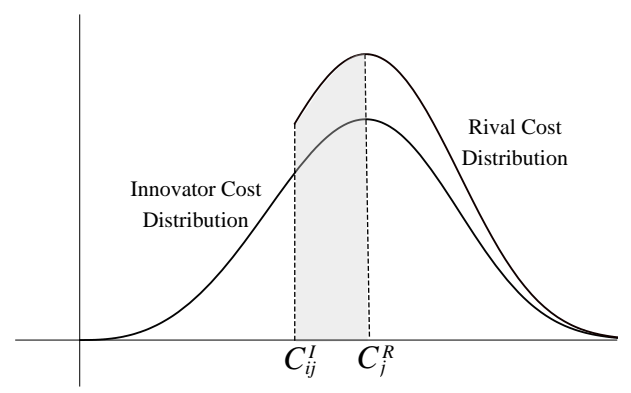

1b. $T_{i}=T_{j}$

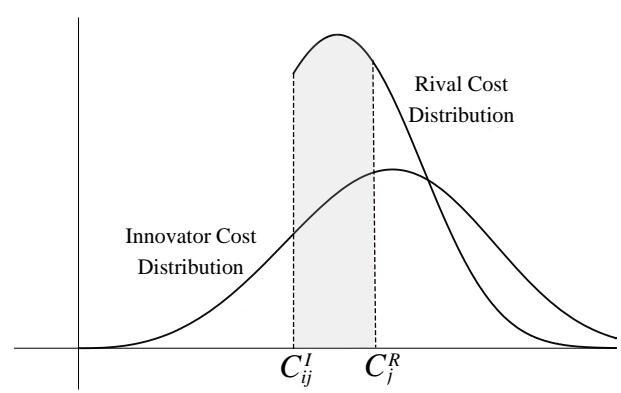

1c. $T_{i}<T_{j}$

Figure 3 - PDF of Cost Distribution $G(c)$ of Innovating $\left(T_{i}\right)$ and Rival $\left(T_{j}\right)$ Firms

The area under the curve gives the ex-ante probability of successful entry by a rival and is determined by the following formula

$$
\int_{c_{i j}^{I}}^{\tilde{c}_{j}^{R}} g_{j}^{R}\left(c \mid c_{i j}^{I}, T_{j} \theta\right) d c=1-e^{-T_{j} w_{j}^{-\theta}\left[\left(\tilde{c}_{j}^{R}\right)^{\theta}-\left(c_{i j}^{I}\right)^{\theta}\right]}
$$


When $c_{i j}^{I}$ decreases, the ex-ante probability of successful entry by the rivals increases, so that more productive innovators are more likely to face more rivals. The intuition behind is that more profitable firms will face a higher number of entrants than less profitable firms ${ }^{7}$. Assuming that the number of potential (ex-ante) rivals in each country $j$ is exogenously given by $R_{j}{ }^{8}$, then each innovating firm can expect to compete against the following number of rivals

$$
r_{i j}(\omega)=R_{j}\left[1-e^{-T_{j} w_{j}^{-\theta}\left[\left(\tilde{c}_{j}^{R}\right)^{\theta}-\left(c_{i j}^{I}\right)^{\theta}\right]}\right]
$$

Before moving to the next section, it bears going through a couple of different properties of the rivals and their production capabilities ${ }^{9}$.

Result 1: The number of rivals $r_{i j}(\omega)$ and their average efficiency increases as the state of technology $T_{j}$ increases.

Result 2: The number of rivals $r_{i j}(\omega)$ increases with the cutoff condition of rival entry $\tilde{c}_{j}^{R}$.

Result 3: The number of rivals $r_{i j}(\omega)$ and their productivity increases with the productivity parameter of the innovating firm.

To summarize these results, more productive innovating firms not only face more rivals, but these rivals are also more productive on average. Innovating firms can reduce the number of rivals they face by increasing the cutoff condition for rival entry. These results help set-up some of the key properties to be uncovered in the simulations. As I move forward, I consider the case where $c_{i j}^{I}<\tilde{c}_{j}^{R}$ so that at least one rival exists at all times.

\footnotetext{
${ }^{7}$ This is supported in the literature by Luttmer (2007) who claims that there are stronger incentives for entry by imitators when the incumbent firm is larger and more profitable. This is also supported in Costinot et al. (2012) who model 'follower' firms in a similar manner where they do not exceed the productive capabilities of the innovating firm.

${ }^{8}$ One could also make it proportional to market size $Y_{j}$ or allow for rivals from outside countries who adhere to the same conditions with bounded distributions

${ }^{9}$ Proofs can be found in the Appendix
} 


\subsection{The Distributions of Markups, Prices and Profits}

The rivals in each country $j$ ensure that the innovating firm does not charge an unfair markup. I assume that the two types of firms will compete in price (Bertrand). The innovating firm only needs to compete against the low-cost rival firm, since all of the other rivals will be unable to match their costs. I denote the marginal cost function of the low-cost rival in country $j$ as $c_{i j}^{R *}$. The price will be determined as the minimum of the low cost rival's cost function and the CES/monopolistic price of the innovating firm. I denote the price under the Bertrand competition scenario as $p_{i j}^{B}$, while the price in the monopoly scenario is written as $p_{i j}^{M}$. Under this scenario, prices are

$$
p_{i j}(\omega)=\min \left\{p_{i j}^{B}=c_{i j}^{R *}, p_{i j}^{M}=\bar{m} c_{i j}^{I}\right\}
$$

With markup

$$
m_{i j}(\omega)=\min \left\{m_{i j}^{B}=\frac{c_{i j}^{R *}}{c_{i j}^{I}}, \bar{m}=\frac{\sigma}{\sigma-1}\right\}
$$

Where $\bar{m}$ is the Dixit-Stiglitz CES markup. This price leads to the following possible profit outcomes for the innovating firm in country $j^{10}$

$$
\pi_{i j}^{I}(\omega)= \begin{cases}\pi_{i j}^{B}=\left(\frac{m_{i j}^{B} c_{i j}^{I}}{P_{j}}\right)^{1-\sigma}\left(\frac{m_{i j}^{B}-1}{m_{i j}^{B}}\right) Y_{j}-f_{i j}^{*} & \frac{c_{i j}^{R *}}{c_{i j}^{I}} \leq \frac{\sigma}{\sigma-1} \\ \pi_{i j}^{M}=\left(\frac{\bar{m} c_{i j}^{I}}{P_{j}}\right)^{1-\sigma}\left(\frac{\bar{m}-1}{\bar{m}}\right) Y_{j}-f_{i j}^{*} & \frac{c_{i j}^{R *}}{c_{i j}^{I}}>\frac{\sigma}{\sigma-1}\end{cases}
$$

The price, markup and firm profits are all determined by the cost ratio of the low-cost rival and innovating firm. If the cost function of the low cost rival is greater than the monopolistic price, than the innovating firm will be able to charge a monopolistic price and obtain monopolistic profits. However, if the cost function of the low-cost rival is lower than the monopolistic price, then the innovating firm obtains Bertrand profits.

In order to determine when the low-cost rival's cost functions is greater than or less than the monopolistic prices, I need to define the distribution of this cost ratio. Using the CDF of the low-cost imitator

\footnotetext{
${ }^{10}$ Note that the fixed cost values will differ for firms who export versus firms who conduct FDI. For general purposes, I use the term $f_{i j}^{*}$ which can be interchanged with the type of innovating firm where $\left(\frac{w_{j}}{w_{i}}\right)^{\sigma-1} f_{i j}^{F}>d_{i j}^{\sigma-1} f_{i j}^{X}$
} 
$G_{i j}^{R *}\left(c_{i j}^{R *}\right)^{11}$ combined with the cost distribution of the innovating firm ${ }^{12}$, the PDF of the cost ratio (and subsequently, the markup under Bertrand competition) is

$$
h\left(\frac{c_{i j}^{R *}}{c_{i j}^{I}}\right)=h\left(m_{i j}^{B}\right)= \begin{cases}\frac{r_{i j} T_{i} T_{j} \theta\left(w_{i} w_{j} d_{i j}\right)^{\theta}\left(m_{i j}^{B}\right)^{\theta-1}}{\left[r_{i j} T_{j}\left(w_{i} d_{i j}\right)^{\theta}\left(\left(m_{i j}^{B}\right)^{\theta}-1\right)+T_{i} w_{j}^{\theta}\right]^{2}} & \text { for } 1 \leq m_{i j}^{B} \leq \bar{m} \\ \int_{m}^{\infty} \frac{r_{i j} T_{i} T_{j} \theta\left(w_{i} w_{j} d_{i j}\right)^{\theta}\left(m_{i j}^{B}\right)^{\theta-1}}{\left[r_{i j} T_{j}\left(w_{i} d_{i j}\right)^{\theta}\left(\left(m_{i j}^{B}\right)^{\theta}-1\right)+T_{i} w_{j}^{\theta}\right]^{2}} d m_{i j}^{B} & \text { for } m_{i j}^{B}=\bar{m} \\ 0 & \text { for } m_{i j}^{B}>\bar{m}\end{cases}
$$

With a mass point at $\bar{m}$. Notice that the distribution of the markup is entirely independent of the marginal costs drawn by the innovating firm and low-cost rival. Also, in the symmetric case with no trade costs and one rival, I have $h\left(m_{i j}^{B}\right)=\theta\left(m_{i j}^{B}\right)^{-\theta-1}$ which is identical to the Pareto density for markups obtained in BEJK. Figure 4 shows the distribution of $h\left(m_{i j}^{B}\right)$ for varying levels of $r_{i j}$.

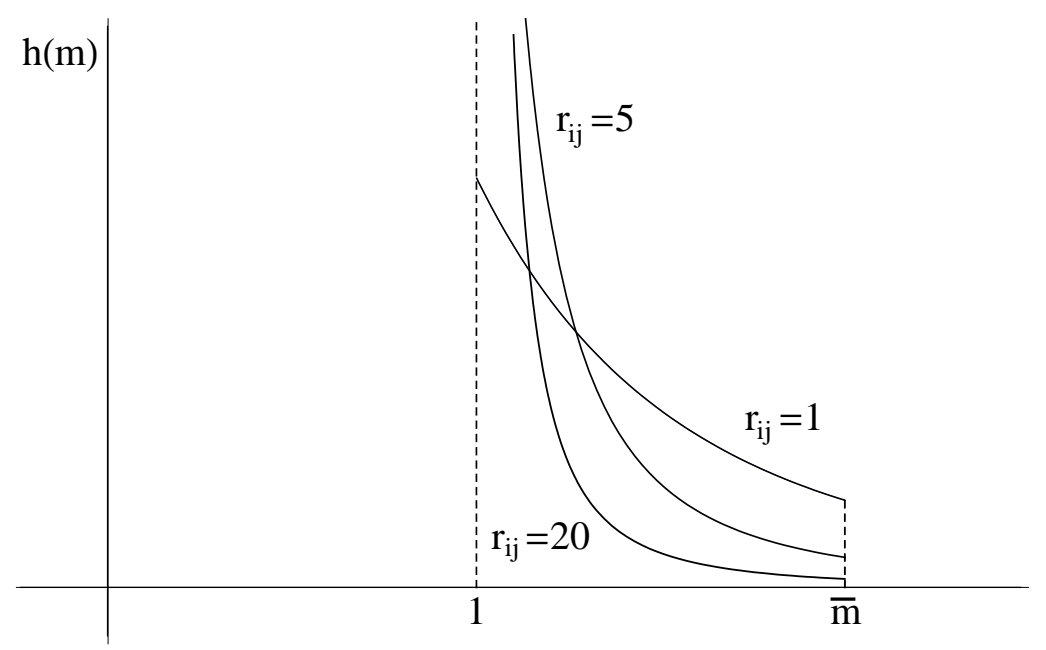

Figure 4: Density of the Markup

Integrating $h\left(m_{i j}\right)$ over the values from $\bar{m}$ to $\infty$ gives the probability that the innovating firm in country $i$ charges the monopolistic markup in country $j$ and achieves profit $\pi_{i j}^{M}$. I denote this probability as $\phi_{i j}$.

\footnotetext{
${ }^{11}$ I use the formulation from Rinne (2009) on pages 224 and 237 which provides the CDF for the first order statistic for Weibull distributions and gives me

$$
G_{i j}^{R *}\left(c_{i j}^{R *} \mid c_{i j}^{I}, r_{i j}, T_{j}, \theta\right)=1-e^{-r_{i j} T_{j} w_{j}^{-\theta}\left[\left(c_{i j}^{R *}\right)^{\theta}-\left(c_{i j}^{I}\right)^{\theta}\right]}
$$

${ }^{12}$ See Appendix section A.2 for derivation
} 


$$
\phi_{i j}=\operatorname{Pr}\left[m_{i j}^{B} \geq \bar{m}\right]=\int_{\bar{m}}^{\infty} h\left(m_{i j}^{B}\right) d m_{i j}^{B}=\frac{T_{i} w_{j}^{\theta}}{r_{i j} T_{j}\left(w_{i} d_{i j}\right)^{\theta}\left(\bar{m}^{\theta}-1\right)+T_{i} w_{j}^{\theta}}
$$

This value is identical to the probability that a supplier charges the unconstrained markup in DBR. Having defined when the markup is Bertrand and when the markup will be CES, I can now rewrite the innovating firm's profit equation as

$$
\begin{aligned}
\mathrm{E}\left[\pi_{i j}^{I}(\omega)\right] & =\phi_{i j} \pi_{i j}^{M}+\left(1-\phi_{i j}\right) \mathrm{E}\left[\pi_{i j}^{B}\right] \\
& =\left(\frac{c_{i j}^{I}}{P_{j}}\right)^{1-\sigma} \alpha_{j} Y_{j}\left[\phi_{i j} V(\bar{m})+\left(1-\phi_{i j}\right) V\left(\bar{m}_{i j}^{B}\right)\right]-f_{i j}^{*}
\end{aligned}
$$

where $V(x)=x^{-\sigma}(x-1)$ and $\bar{m}_{i j}^{B}=\mathrm{E}\left[m_{i j}^{B} \mid m_{i j}^{B} \leq \bar{m}\right]$ is the expected value of the markup when it is less than the CES markup ${ }^{13}$. This leads to the next set of results.

Result 4: The probability the innovating firm charges the CES markup in country $j$ is decreasing in contestability $r_{i j}{ }^{14}$.

Result 5: The probability the innovating firm charges the CES markup in country $j$ increases as the cutoff condition for rival entry decreases and decreases as the innovating firm becomes more productive $\left(\right.$ lower costs) ${ }^{15}$.

Result 6: The innovating firm's expected profit $\mathrm{E}\left[\pi_{i j}^{I}(\omega)\right]$ is decreasing in contestability $r_{i j}$.

Result 7: The price of variety $\omega$ charged to consumers in country $j$ is decreasing in contestability $r_{i j}$

\footnotetext{
${ }^{13}$ The expected value of this is given by the formula $\frac{\int_{1}^{\bar{m}} m_{i j} h\left(m_{i j}\right)}{1-H(\bar{m})} d m_{i j}$ which has no closed-form solution

${ }^{14}$ This result is similar to the findings in DBR who similarly show that lower markups occur with increased contestability.

${ }^{15}$ It may seem counterintuitive that more productive firms are less likely to be monopolists, but note that the expected markup for the innovating firm increases with their productivity so that they are still guaranteed more profits than low productivity firms.
} 
To sum up the results, the number of rivals negatively effects the innovating firm's expected profits, so that holding the innovating firm's productivity constant, they will want to reduce the number of rivals. Note that despite the increased contestability, innovating firms with higher productivities still receive larger profits due to CRS and capturing a larger market share. This completes the set-up for the first stage of the model. The next section looks at when the innovating firm decides to patent.

\subsection{The Decision to Patent}

Up until this point, the innovating firm's operating profits depends on the number of rivals which is dependent on the firm's productivity draw and zero-profit condition. Patenting is a mechanism that allows the innovating firm to reduce the number of rivals they face in any given market $j$ by increasing the zero-profit condition ${\tilde{c_{i j}}}^{R}$. When firms patent in country $j$, they pay a fixed cost $f_{j}^{P}$ and in return, rival firms will have to pay an additional overhead cost of $f_{j, p a t}^{R}$ where $f_{j, p a t}^{R} \geq f_{j, n o t}^{R}$. One way to interpret this is that patenting causes the rival firms to pay either additional legal or licensing fees, in order to produce around the patent. The better the patent protection, the greater the cost to produce around the patent. This higher cost $f_{j, p a t}^{R}$ decreases the threshold cost condition for rival firms, which by Result 2, reduces the number of rivals. This reduction in rivals has a doubly positive effect on firm profits as it not only increases the probability for the innovating firm to charge their optimal markup, but also increases the expected markup should the firm operate in Bertrand competition. The expected profits from patenting are:

$$
\mathrm{E}\left[\pi_{i j, p a t}^{I}(\omega)\right]=\phi_{i j, p a t} \pi_{i j}^{M}+\left(1-\phi_{i j, p a t}\right) \mathrm{E}\left[\pi_{i j, p a t}^{B}\right]-f_{i j}^{*}-f_{j}^{P}
$$

The firm will patent when $\pi_{i j, p a t}^{I}(\omega)-\pi_{i j, n o t}^{I}(\omega) \geq f_{j}^{P}$. Figure 3 plots the two expected profits for when the firm elects to patent and when they do not. Also included are the entry conditions for the rival firms where the $Z^{R}$ is the corresponds to the marginal cost sufficient to cover the fixed per-period overhead costs so that $Z_{j, p a t}^{R}>Z_{j, n o t}^{R}$. When productivity of the innovating firm $z_{i}^{I}$ is greater than or equal to the corresponding patenting threshold $z_{i j}^{P}$, then the innovating firm will elect to patent. 


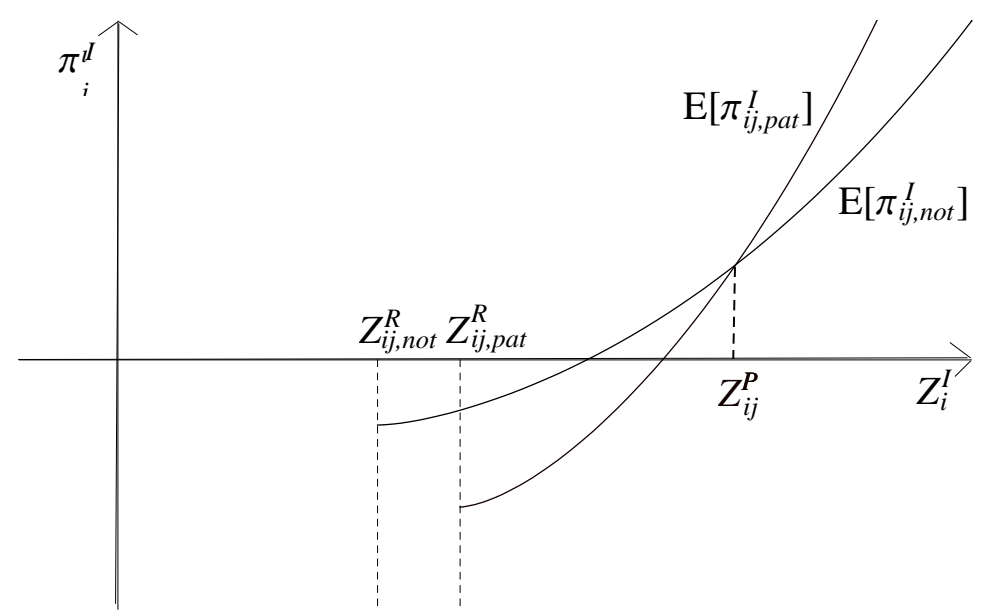

Figure 5: Innovating Firm's Expected Profit from Patenting

Analytically, this patenting cutoff condition will be defined as $c_{i j}^{P}$ so that whenever $c \leq c_{i j}^{P}$ innovating firms will elect to patent ${ }^{16}$.

Note that country $j$ 's patent protection will have no effect on the firm's decision to enter into a foreign market, thereby preserving the properties uncovered in the 'new' new trade theory models. I am then left with four types of firms in every market: Non-patenting exporting and FDI firms where $c_{i j}^{I}>c_{i j}^{P}$ and patenting exporting and FDI firms where $c_{i j}^{P} \geq c_{i j}^{I} \cdot{ }^{17}$.

\footnotetext{
${ }^{16}$ To solve for the patenting cutoff condition, set the patent profits equal to the non-patent profits.

$$
c_{i j}^{P}=\left(\frac{f_{j}^{P}}{\alpha_{j} Y_{j}}\right)^{\frac{1}{1-\sigma}} P_{j}\left\{\phi_{i j, p a t}\left[V(\bar{m})-V\left(\bar{m}_{i j, p a t}^{B}\right)\right]-\phi_{i j, n o t}\left[V(\bar{m})-V\left(\bar{m}_{i j, n o t}^{B}\right)\right]+V\left(\bar{m}_{i j, p a t}^{B}\right)-V\left(\bar{m}_{i j, n o t}^{B}\right)\right\}^{\frac{1}{\sigma-1}}
$$
}

Next, since not all firms elect to patent, it must be the case that $c_{i j}^{P}$ is less than the market entry condition $c_{i j}^{E}$. Given the entry condition

$$
c_{i j}^{E}=\left(\frac{f_{i j}}{\alpha_{j} Y_{j}}\right)^{\frac{1}{\sigma-1}} P_{j}\left[\phi_{i j, n o t} V(\bar{m})+\left(1-\phi_{i j, n o t}\right) V\left(m_{i j, n o t}^{B}\right)\right]^{\frac{1}{\sigma-1}}
$$

It must be the case that

$$
f_{j}^{P} \geq f_{i j}^{*}\left[\frac{\phi_{i j, p a t}\left(V(\bar{m})-V\left(m_{i j, p a t}^{B}\right)\right)+V\left(m_{i j, p a t}^{B}\right)}{\phi_{i j, n o t}\left(V(\bar{m})-V\left(m_{i j, n o t}^{B}\right)\right)+V\left(m_{i j, n o t}^{B}\right)}\right]
$$

${ }^{17}$ Depending on the level of patent protection, there is no pre-determined ranking of productivities for each type of firm. It is simply the case that $z_{i j, \text { not }}^{E X P}<z_{i j, \text { not }}^{F D I}$ and $z_{i j, \text { not }}^{E X P}<z_{i j, p a t}^{E X P}$ and $z_{i j, n o t}^{F D I}<z_{i j, p a t}^{F D I}$. 
A closed-form solution to the equilibrium does not exist. To solve for the equilibrium, one can normalize the wages by introducing an homogeneous good that is freely traded and then introduce a free-entry condition $^{18}$. Then solve for the cutoff productivities for each type of firm in a system of equations. Given the following parameters: $T, \theta, \sigma, L, d, R$ and the various fixed costs, one can then solve for a numerical equilibrium.

\section{Properties of the Model}

In order to uncover some of the properties of the model in equilibrium, this section runs several simulations with different parameter values to assess when firms will patent and how country and industry differences will impact the patenting decision. I start by first looking at the closed economy simulation with attention on industry-level differences. I then analyze the open economy scenario that accounts for country-level differences.

\subsection{Closed Economy with Different Industry Parameters}

To parameterize the model, I first normalize the wages and set the market size $L$ equal to 100 . I next set the fixed costs for rival entry equal to 20 , innovating firm entry equal to 50 , patenting cost equal to 10 and patenting increasing the entry costs for rivals by $35 x^{19}$. Next, I set the number of potential rivals as a

$$
\begin{aligned}
& \underbrace{{ }^{18} \text { Specifically, the free-entry condition is: }}_{\text {Domestic-Only Firms }} \underbrace{Q\left(z_{i, n o t}^{D}, z_{i, p a t}^{D}\right) B_{i, n o t}+Q\left(z_{i, p a t}^{D}, \infty\right) B_{i, p a t}}_{\text {FDI Firms }}+\underbrace{\sum_{i \neq j} d_{i j}^{1-\sigma}\left[Q\left(z_{i j, n o t}^{X}, z_{i j, p a t}^{X}\right) B_{j, n o t}+Q\left(z_{i j, p a t}^{X}, \infty\right) B_{j, p a t}\right]}_{\text {Exporting Firms }} \\
& +\underbrace{}_{\sum_{i \neq j}\left[1-d_{i j}^{1-\sigma}\right]\left[Q\left(z_{i j, n o t}^{F}, z_{i j, p a t}^{F}\right) B_{j, n o t}\right.}+Q\left(z_{i j, p a t}^{F}, \infty\right) B_{j, p a t}] \\
& -\left[F\left(z_{i, n o t}^{D}\right) f_{i}^{D}+F\left(z_{i, p a t}^{D}\right)\left(f_{i}^{D}+f_{i}^{P}\right)+\sum_{i \neq j} F\left(z_{i j, n o t}^{X}\right) f_{i j}^{X}+\sum_{i \neq j} F\left(z_{i j, p a t}^{X}\right)\left(f_{i j}^{X}+f_{j}^{P}\right)+\sum_{i \neq j} F\left(z_{i j, n o t}^{F}\right) f_{i j}^{F}+\sum_{i \neq j} F\left(z_{i j, p a t}^{F}\right)\left(f_{i j}^{F}+f_{j}^{P}\right)\right]=f_{i}^{E}
\end{aligned}
$$

Where $Q(x, y)=\int_{x}^{y} z^{\sigma-1} \partial F(z)$ and $B_{i}$ is the demand level of country $J$ given by

$$
B_{i}=\frac{\alpha_{i} Y_{i}}{P_{i}^{1-\sigma}}\left[\phi_{i i, n o t} H(\bar{m})+\left(1-\phi_{i i, n o t}\right) H\left(\bar{m}_{i i, n o t}^{B}\right)\right]
$$

\footnotetext{
${ }^{19}$ Note that I set the industry share $\alpha_{i}$ equal to 1 so that the entire market consists of one good. We can adjust the fixed costs and and industry shares anyway we like and generate similar outcomes. Therefore, the values for the fixed costs should not be interpreted in any meaningful way, other than simply as a set of parameter values that yields a numerical solution.
} 
proportion of the market size L. Both Atkeson and Burstein (2008) and DBR assume potential rivals, so I set the proportion equal to $20 \%$. Next, I set the technology parameter $T_{i}$ equal to one.

Figure 6 plots how the number of rivals and markups change as the productivity of the innovating firm $z_{i}^{I}$ increases. As $z_{i}^{I}$ gets larger, the number of rivals increases, while the markup declines until the dotted line, at which the innovating firm patents, clearing the market of rivals and allowing the innovating firm to charge the full monopolistic mark-up. From there, rival firms gradually start returning.

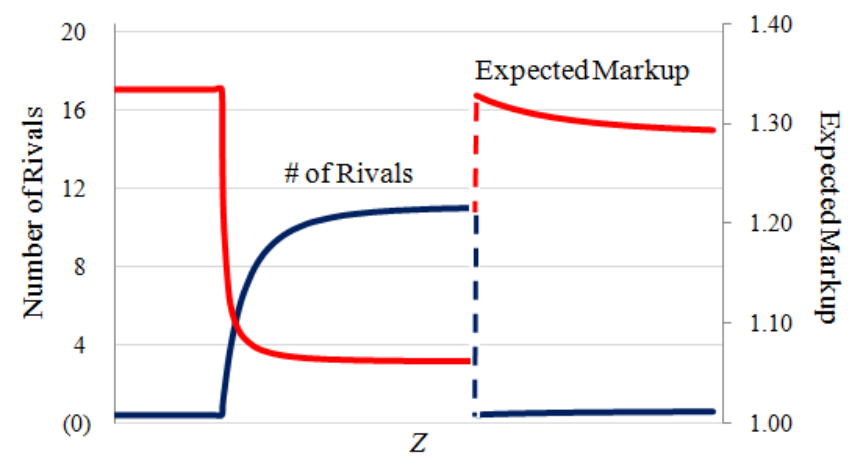

Figure 6: Number of Rivals and Expected Markup by $Z$, for $\theta=3.60$ and $\sigma=4$

The industry variants I look at include the elasticity of substitution $\sigma$ and variance in production $\theta$. In the baseline scenario, I set $\theta=3.60$ and $\sigma=4$. In regards to changes for each, I expect the following to occur: As $\sigma$ increases, the monopolistic mark-up for rival firms and innovating firms decreases to a certain point ${ }^{20}$, leading to fewer rivals faced by innovating firms. The expected markup for innovating firms will stay roughly the same as the lower monopolistic markup is made up by the increased Bertrand competition markup resulting from fewer rivals. As competition declines, the proportion of firms who patent will decrease, until the point where increased $\sigma$ leads to more potential rivals, at which patenting will once again become more common. In other words, we expect to see a U-shaped pattern of patenting as $\sigma$ changes. For changes in $\theta$, higher $\theta$ leads to reduced heterogeneity in productivity, meaning that there are fewer differences in firm productivities within that industry. While $\theta$ will not affect the number of rivals faced by the innovating firm, it will effect their productivities. For higher values of $\theta$, the competition is more fierce, leading to higher entry conditions for the innovating firm. Unless the innovating firm can charge a substantially high markup (requiring low $\sigma$ ), these firms will decline entry into the market and the number of firms (and thereby number of patenting firms) will decline unless the monopolistic markup makes it worthwhile for these firms to enter. Hence, we should expect to see low levels of entry and patenting for high values of $\theta$ and high values of $\sigma$, but high-levels of patenting for high values of $\theta$ and low values of $\sigma$ due to the fact that the monopolistic markup becomes more important at that point. Simulating these values, I generate

\footnotetext{
${ }^{20}$ Specifically where $\frac{d z_{i}^{R}}{d \sigma}=0$
} 
the following table:

Table 1: Closed Economy Simulation of Patenting

\begin{tabular}{|c|c|c|c|c|c|c|c|c|c|}
\hline & \multicolumn{3}{|c|}{$\theta=3.60$} & \multicolumn{3}{|c|}{$\theta=8.28$} & \multicolumn{3}{|c|}{$\theta=12.86$} \\
\hline & $\sigma=3$ & $\sigma=5$ & $\sigma=8$ & $\sigma=3$ & $\sigma=5$ & $\sigma=8$ & $\sigma=3$ & $\sigma=5$ & $\sigma=8$ \\
\hline P(Entry \| Innovator) & $2.278 \%$ & $16.054 \%$ & $33.515 \%$ & $0.001 \%$ & $0.789 \%$ & $7.396 \%$ & $0.000 \%$ & $0.035 \%$ & $1.322 \%$ \\
\hline $\begin{array}{l}\text { P(Entry \| Rival) } \\
\text { at Patent Kink }\end{array}$ & $61.781 \%$ & $45.576 \%$ & $50.647 \%$ & $60.081 \%$ & $39.410 \%$ & $44.896 \%$ & $58.358 \%$ & $28.981 \%$ & $36.633 \%$ \\
\hline $\begin{array}{l}\% \text { of Entrants } \\
\text { that Patent }\end{array}$ & $7.882 \%$ & $15.292 \%$ & $27.511 \%$ & $7.135 \%$ & $4.283 \%$ & $10.655 \%$ & $23.639 \%$ & $1.404 \%$ & $4.928 \%$ \\
\hline
\end{tabular}

The simulations seem to support a U-shaped pattern of patenting by new entrants, with low values of $\theta$ and low values of $\sigma$ combined with high values of $\theta$ both yielding the largest proportion of firms who patent. Looking at the entry conditions for the innovating firm, Table 1 also indicates that the industries with the highest absolute number of patents (controlling for potential entrants) will be those that are highly substitutable and have relatively high variability in labor productivity. To further test this U-shaped hypothesis, I plot the propensity to patent based on both $\sigma$ and $\theta$ below in Figure 7 .
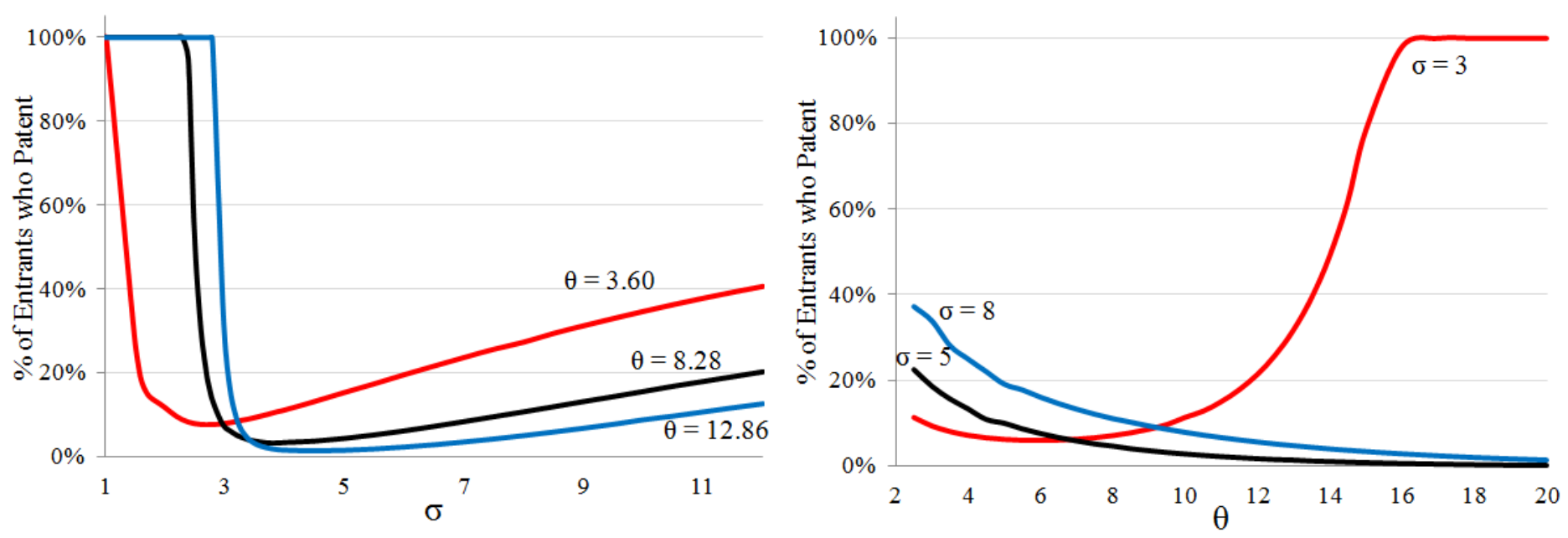

Figure 7: Propensity to Patent for given values of $\sigma$ and $\theta$

The figure on the left provides the U-shaped pattern of patenting indicated in the earlier simulation, while the figure on the right, only shows a U-shaped pattern for relatively low values of $\sigma$. To conclude this section 
on the closed economy, industry patterns of patenting are highly variable with less substitutable industries more likely to patent if they have lower productivity variability (higher $\theta$ ). Similarly, more substitutable industries are also more likely to patent if they have higher productivity variability (lower $\theta$ ). I now turn to the open economy simulations.

\subsection{Open Economy}

For the open economy simulations, I use the same parameter values as before, keeping $\sigma=4$ and $\theta=3.60$, except I now include trade costs of $10 \%$ in the baseline scenario $\left(d_{i j}=1.1\right)$. Note that because of the addition of trade costs, innovating firms will require a higher $z$ to break-even, therefore leading to fewer overall entrants. I focus the simulation on patents originating from country $i$ and ending in country $j$. The key country variables will be population $\left(L_{j}\right)$, which will determine both the number potential rivals and market size, technology level $T_{j}$, trade costs $d_{i j}$, cost to patent $f_{j}^{P}$ and overhead costs to produce around the patent $f_{j, p a t}^{R}$. Unlike the closed-country simulations, the impact of changes to these parameters is expected to be relatively straightforward. As the population or market size increases, the number of rival entrants and innovating firm entrants will increase. Due to the increased number of entrants, more innovating firms would be likely to patent in order to capture a greater share of the increased market size. For the technology parameter, under Result 1, this will increase both the number and composition of the rival firms. This will make it both harder for new innovating firms to enter the market, and more likely that these innovating firms will patent in order to reduce the absolute number of rivals. For trade costs, higher trade costs will have a larger impact on the entry condition than on the patent condition for innovating firms, thereby leading to a greater proportion of patenting firms. The changes to the cost of patenting and the new overhead charge to rival firms will have no effect on the innovating firms' entry condition, but will reduce the patenting condition leading to a higher proportion of entrants who patent. I simulate the effects of these parameter values by first looking at the effects of patenting costs and additional overhead cost for rivals. Table 2 shows the results. 
Table 2: Open Economy Simulation of Patenting

\begin{tabular}{|c|c|c|c|c|c|c|c|c|}
\hline & \multicolumn{4}{|c|}{$L_{j}=10$} & \multicolumn{4}{|c|}{$L_{j}=20$} \\
\hline & \multicolumn{2}{|c|}{$f_{j, \text { pat }}^{R}=25 \times f_{j, \text { not }}^{R}$} & \multicolumn{2}{|c|}{$f_{j, p a t}^{R}=35 \times f_{j, n o t}^{R}$} & \multicolumn{2}{|c|}{$f_{j, p a t}^{R}=25 \times f_{j, \text { not }}^{R}$} & \multicolumn{2}{|c|}{$f_{j, p a t}^{R}=35 \times f_{j, \text { not }}^{R}$} \\
\hline & $f_{j}^{P}=10$ & $f_{j}^{P}=15$ & $f_{j}^{P}=10$ & $f_{j}^{P}=15$ & $f_{j}^{P}=10$ & $f_{j}^{P}=15$ & $f_{j}^{P}=10$ & $f_{j}^{P}=15$ \\
\hline $\mathrm{P}($ Entry \| Innovator $)$ & $4.988 \%$ & $4.988 \%$ & $4.988 \%$ & $4.988 \%$ & $4.953 \%$ & $4.953 \%$ & $4.953 \%$ & $4.953 \%$ \\
\hline $\begin{array}{l}\text { P(Entry \| Rival) } \\
\text { at Patent Kink }\end{array}$ & $53.242 \%$ & $53.386 \%$ & $53.223 \%$ & $53.376 \%$ & $82.531 \%$ & $82.679 \%$ & $82.445 \%$ & $82.648 \%$ \\
\hline $\begin{array}{l}\% \text { of Entrants } \\
\text { that Patent }\end{array}$ & $14.415 \%$ & $8.261 \%$ & $15.238 \%$ & $8.708 \%$ & $36.625 \%$ & $19.630 \%$ & $46.297 \%$ & $23.202 \%$ \\
\hline
\end{tabular}

Unsurprisingly, the open country simulation shows that reducing the cost to patent for innovating firms and increasing the overhead costs for rivals leads to increased patenting and has virtually no impact on entry by either innovators or rivals. Increasing population also has a similar impact on the proportion of patenting firms with higher population markets leading to both reduced entry conditions for rival and innovating firms, along with a greater proportion of firms who patent. Turning now to the impact of technology and trade costs, Figure 8 shows how the proportion of patents changes as the level of technology and trade costs increase.
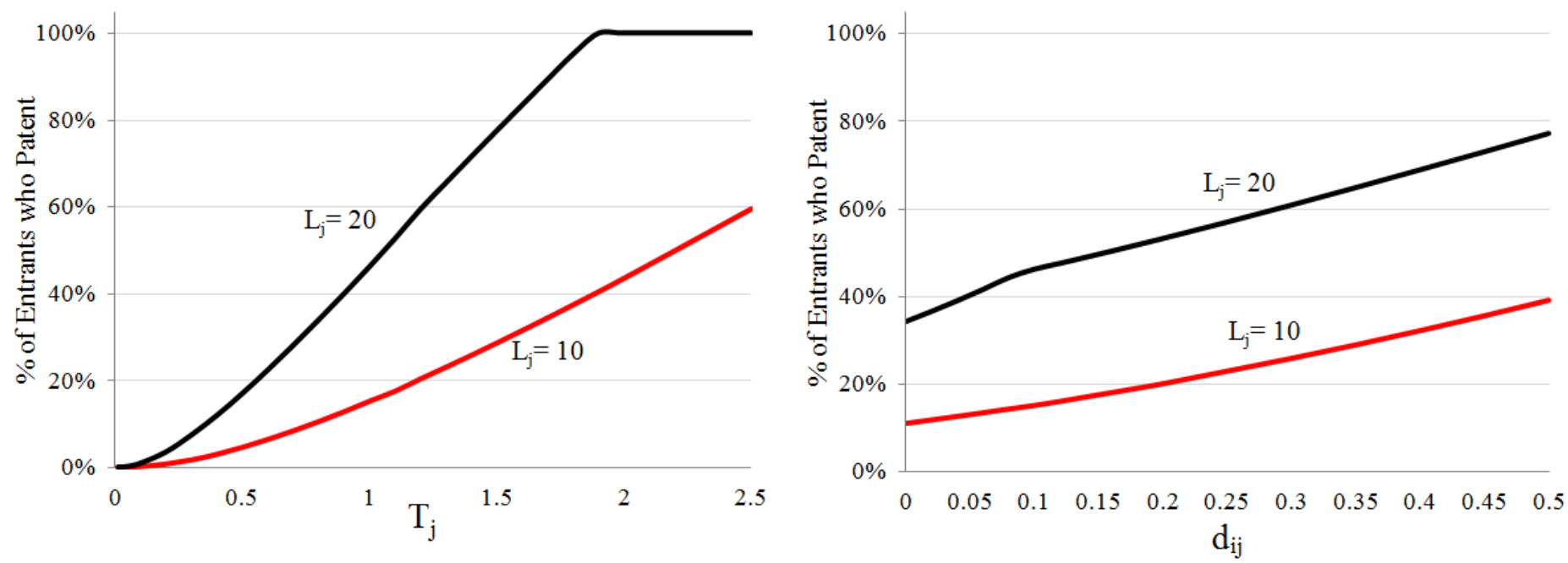

Figure 8: Propensity to Patent Based on Technology Level $T_{j}$ and Trade Costs $d_{i j}$

Unsurprisingly, the impact of both technological changes and trade effects is monotonically increasing on the 
percentage of firms who patent. To conclude, the simulations tell us that countries that are technologically advanced, have good patent protection (in the form of low costs for innovating firms and higher overhead costs for rival firms) and lots of competition from rivals experience a higher proportion of patenting firms. Similarly, industries with very low elasticities of substitution or a combination of high elasticities and high variance in productive capabilities will tend to patent more. All told, these properties provide testable implications that can be verified using patent data. The next section outlines a method to generate market-based measures of country-level patent protection for the period 1996 to 2005.

\section{Data and Estimation Strategy}

The model predicts that country-level and industry-level differences all play a role in determining which firms patent and where. The objective of the empirical section is to apply actual patent data to the model and back out these predictions. I start by first deriving country-level measures of patent protection. I use destination fixed effects and normalize the measure of patent protection to be the reduction in the number of actual rivals that innovating firms face so that if the number of rivals an innovating firm faces after patenting decreases by 100\%, then the country has an IPR rating of 1 (100\%). Unlike other Ricardian trade models, this specification does not incorporate any trade flows. It merely considers market size, distance, wages and technology states as being the key determinants of whether firms patent.

Using the formulas for productivity distributions and substituting destination country fixed effects, I run a non-linear least squares estimation on the following measure of bilateral patent flows $M_{i j}$ (where $M_{i}$ is the number of domestic patents taken out in country $i$ ):

$$
\ln M_{i j}=\ln M_{i}-K_{j} T_{i} X_{j}^{\frac{\theta}{\sigma-1}} w_{i}^{-\theta}\left(\frac{T_{i} w_{j}^{\theta}}{\delta_{j} T_{n} w_{i}^{\theta}\left(\bar{m}^{\theta}-1\right)+T_{i} w_{j}^{\theta}}-\frac{T_{i} w_{j}^{\theta}}{T_{j} w_{i}^{\theta}\left(\bar{m}^{\theta}-1\right)+T_{i} w_{j}^{\theta}}\right)^{\frac{\theta}{\sigma-1}}
$$

where $K_{j}$ is a destination country-time fixed effect ${ }^{21}$ and $\delta_{j}$ is the country-level measure of IPR (defined as $\left.\delta_{j}=r_{j, \text { pat }} / r_{j, n o t}\right)$. In order to have simplified the expression, I assumed trade costs of $5 \%$ for all bilateral pairs. The other parameters of the estimating equation come from the following:

\footnotetext{
${ }^{21}$ Defined as $K_{j}=\left(\frac{f_{j}^{P}}{A-\left(m_{i j}^{B}\right)^{1-\sigma}+\left(m_{i j}^{B}\right)^{-\sigma}}\right)^{\frac{1}{\sigma-1}} P_{j}^{\theta}$
} 
Table 3: Parameter Values and Data Used

\begin{tabular}{lc}
\hline \hline Parameter & Values/Sources \\
\hline$M_{i}^{I}, M_{i j}^{P}$ & PATSAT \\
$\sigma$ & 5 \\
$\theta$ & 8.28 \\
$T_{i}$ & Fieler $(2007)$ \\
$X_{j}, w_{i}$ & World Bank \\
\hline
\end{tabular}

For bilateral patent flows, I use a special subset of the PATSTAT database compiled by WIPO and the EPO. The subset consists of all patent families, or the patents for a single invention applied for over multiple jurisdictions. This patent family database is comprehensive and measures bilateral patent flows for more than 64 destination countries between the years 1996 and 2005. This sample reduces to 28 when I remove countries with too few nonzero observations and member countries in the $\mathrm{EPO}^{22}$. The reason for doing this is that multinational firms can apply for a single patent through the EPO and receive blanket IPR coverage across all of it's member countries. Therefore, the country-level estimates of IPR for member countries of the EPO are going to be significantly underestimated. There are other regional patent agreements that exist that are similar to the EPO such as ARIPO (African Regional Intellectual Property Organization), but no member countries of these regional agreements were found in the data.

Finally, I compare my results to another country-level IPR index provided by Park (2008) whose values are normalized to 1 . This comparison is useful for a couple of reasons. The first is that it provides a benchmark for the IPR estimates from NLLS to compare against. The second purpose is that the index compiled by Park is based on the interpretation of the patent law and environment for the country ${ }^{23}$, while the IPR figures derived in this paper are based on the actual outcomes. I will argue that the differences between the two measures can point to whether countries are patenting to little or too much abroad. This is particularly helpful since many of the countries surveyed in this estimate are developing countries.

\footnotetext{
${ }^{22}$ Member countries that were excluded from the data are: Austria (AUT), Belgium (BEL), Bulgaria (BGR), Switzerland (CHE), Cyprus (CYP), Czech Republic (CZE), Germany (DEU), Denmark (DNK), Estonia (EST), Spain (ESP), Finland (FIN), France (FRA), Great Britain (GBR), Greece (GRC), Hungary (HUN), Ireland (IRL), Iceland (ISL), Italy (ITA), Lithuania (LTU), Luxembourg (LUX), Latvia (LVA), Netherlands (NLD), Norway (NOR), Portugal (PRT), Sweden (SWE), Slovenia $(\mathrm{SVN})$, Slovakia (SVK), Turkey (TUR)

${ }^{23}$ Specifically, the values are compiled using five separate criteria: coverage, membership in international treaties, duration of protection, enforcement and restrictions
} 
Table 4: Estimates of Country IPR Protection (NLLS)

\begin{tabular}{|c|c|c|c|c|}
\hline Country & Country Code & Estimated IPR (NLLS) & IPR (Park) & Difference \\
\hline Argentina & ARG & 0.332 & 0.758 & -0.426 \\
\hline Australia & AUS & 0.584 & 0.833 & -0.249 \\
\hline Bosnia And Herzegovina & $\mathrm{BIH}$ & 0.419 & $\mathrm{~N} / \mathrm{A}$ & $\mathrm{N} / \mathrm{A}$ \\
\hline Brazil & BRA & 0.412 & 0.648 & -0.236 \\
\hline Canada & CAN & 0.495 & 0.924 & -0.429 \\
\hline China & $\mathrm{CHN}$ & 0.554 & 0.653 & -0.099 \\
\hline Costa Rica & CRI & 0.394 & 0.537 & -0.143 \\
\hline Algeria & DZA & 0.686 & 0.604 & 0.082 \\
\hline Egypt & EGY & 0.272 & 0.426 & -0.154 \\
\hline Hong Kong & HKG & 0.286 & 0.736 & -0.45 \\
\hline Croatia & HRV & 0.701 & $\mathrm{~N} / \mathrm{A}$ & $\mathrm{N} / \mathrm{A}$ \\
\hline Indonesia & IDN & 0.614 & 0.486 & 0.128 \\
\hline India & IND & 0.595 & 0.514 & 0.081 \\
\hline Israel & ISR & 0.255 & 0.797 & -0.542 \\
\hline Japan & JPN & 0.817 & 0.927 & -0.11 \\
\hline Korea, Republic Of South & KOR & 0.505 & 0.833 & -0.328 \\
\hline Morocco & MAR & 0.593 & 0.602 & -0.009 \\
\hline Mexico & MEX & 0.400 & 0.733 & -0.333 \\
\hline New Zealand & NZL & 0.733 & 0.802 & -0.069 \\
\hline Philippines & PHL & 0.368 & 0.766 & -0.398 \\
\hline Poland & POL & 0.661 & 0.790 & -0.129 \\
\hline Russian Federation & RUS & 0.683 & 0.730 & -0.047 \\
\hline Singapore & SGP & 0.524 & 0.812 & -0.288 \\
\hline Tajikistan & TJK & 0.718 & $\mathrm{~N} / \mathrm{A}$ & $\mathrm{N} / \mathrm{A}$ \\
\hline Ukraine & UKR & 0.668 & 0.735 & -0.067 \\
\hline Uruguay & URY & 0.524 & 0.626 & -0.102 \\
\hline United States & USA & 0.961 & 0.975 & -0.014 \\
\hline South Africa & $\mathrm{ZAF}$ & 0.643 & 0.826 & -0.183 \\
\hline Mean & & 0.550 & 0.723 & -0.173 \\
\hline Correlation & & & & 0.358 \\
\hline
\end{tabular}

The results show that for most countries, the estimates for IPR based on actual patent flows is lower than the measures used in Park (2008). Figure 9 below plots the results with the IPR measures from Park (2008) and a 45-degree line to show how many of the new results tend to systematically underestimate Park's IPR measures. 


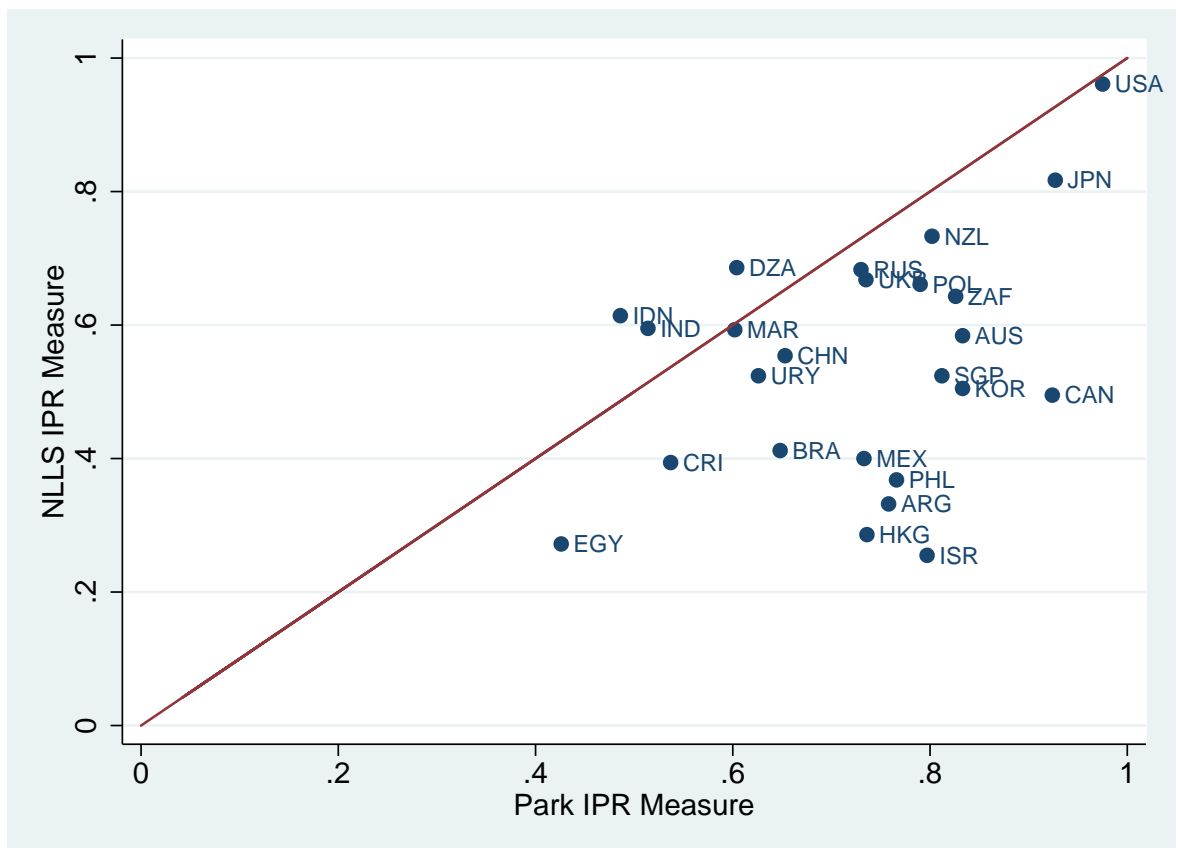

Figure 9: IPR Estimate Comparison

This graph highlights some suggestive evidence that not enough international patenting is taking place abroad, since otherwise the market-based IPR measures would not systematically underestimate the Park index. It may be the case that firms are purposefully withholding patents for some unknown reason. This has potential implications for whether Article 66.2 of the TRIPS agreement, which states that wealthy countries should provide incentives for firms to transfer technology to developing countries. There has been vigorous debate as to whether or not wealthy countries are fulfilling their end of the bargain. While patents alone do not constitute specific technology transfer, patenting is typically seen as a precursor for future diffusion through other investments. Given that the specification is generalized and does not take into account industry-specific factors or bilateral trade agreements, there is still more work to be done to investigate whether or not this is actually the case. Nevertheless, the model provides a framework for future analysis of this type which can provide additional insight as to how IP should be measured abroad.

\subsection{Reduced Form Estimation}

Next, I want to test whether the patent data itself holds to some of the predictions of the model, mainly looking at whether the country-specific and industry-specific factors identified in the model influence patenting in the way predicted. The model has numerous predictions regarding the proportion of patents flowing to countries based on their market size, technology base, IP protection, trade costs and other industry factors 
such as elasticity substitution and labor variability. Currently, there exists data to test almost all of the predictions, with the exception of the number of rivals (which may be imputed from the market size of the destination country) and labor variability (industry fixed effects are used instead) ${ }^{24}$. To run the test, I use a logit regression where the dependent variable is the proportion of patents by origin country-industry flowing to the destination country. I also incorporate a newly available industry-technology crosswalk from Lybbert and Zolas (2014) which allows me to incorporate industry-specific attributes to patent flows. The basic reduced form of the estimating equation is:

$$
\frac{P A T_{i j k t}}{P A T_{i k t}}=\alpha+\delta_{1} \ln \left(G D P_{j t}\right)+\delta_{2} \ln \left(I P P_{j t}\right)+\delta_{3} T E C H_{j t}+\delta T R A D E_{i j}+\delta_{5} E P O_{j t}+\delta_{4} \sigma_{k}+\alpha_{t}+\alpha_{k}+\varepsilon_{i j k t}
$$

Where $i$ is the origin country, $j$ is the destination country, $k$ is the industry (as measured by 4-digit SITC Rev. 2) and $t$ is the year. For $G D P, I P R$ and $T E C H$, I use the same data as in the previous exercise and use the Park IPR index since the coverage is better. The variable $T R A D E$ includes the numerous trade costs between countries $i$ and $j$ such as distance, whether they share a border, language dummies and trade agreements. I also include a dummy variable for whether the destination country is a member of the EPO since countries are more likely to patent through the EPO than individual member nations. I include industry measures such as the elasticity of substitution, $\sigma$, which is gathered from Broda and Weinstein (2006). In addition to this industry-specific measure, I also include the Rauch classification (Rauch 1999) which classifies goods whether they are priced on an organized exchange, referenced priced or are differentiated products. Finally, I include year fixed-effects, as well as two-digit industry fixed effects.

For the patent data, I use the same PATSTAT database of patent family flows and expand the number of destination countries to the full sample. The patent flows are organized by the International Patent Classification (IPC) system, which classifies technologies. To convert this classification into industry classifications, I use the technology-industry concordance from Lybbert and Zolas (2014) which converts 4-digit IPCs into 4-digit Standard International Trade Classification (SITC) Revision 2. This concordance uses keyword extraction algorithms to read through patents, collect the relevant keywords and then match them with the industry descriptions. Once the patents are concorded, I am left with country-industry-year patent totals and flows. My initial frame began with 131 countries, 1189 four-digit industries over the period 1996-2005, resulting in more than 200 million possible observations. However, due to the fact that very few countries patent in all industries (or at all), my unbalanced panel contains roughly 18 million observations.

\footnotetext{
${ }^{24}$ It may be possible to estimate these missing variables with a structural estimation, but that will be left for a future paper
} 
I also run the regression using a "balanced" panel which I define as having nonzero values of $P A T_{i k t}$ for all of the years in the sample. There are approximately 11 million observations in the balanced panel. Table 5 below shows the results from the unbalanced and balanced estimation. 
Table 5: Logit Regression of Proportions of Patents Flowing to Each Country Dependent Variable: Proportion of Country-Industry Patent Flows

\begin{tabular}{|c|c|c|c|c|c|c|}
\hline \multirow{2}{*}{$\begin{array}{l}\text { Explanatory } \\
\text { Variable }\end{array}$} & \multicolumn{3}{|c|}{ Unbalanced } & \multicolumn{3}{|c|}{ Balanced } \\
\hline & $(1)$ & $(2)$ & $(3)$ & $(4)$ & $(5)$ & $(6)$ \\
\hline \multirow[t]{2}{*}{ log Destination GDP } & $0.634^{* * *}$ & $0.670^{* * *}$ & $0.775^{* * *}$ & $0.706^{* * *}$ & $0.735^{* * *}$ & $0.816^{* * *}$ \\
\hline & $(0.000806)$ & $(0.000829)$ & $(0.000936)$ & $(0.000927)$ & $(0.000949)$ & $(0.00104)$ \\
\hline \multirow[t]{2}{*}{ Destination IPR } & $0.318 * * *$ & $0.250^{* * *}$ & $0.349^{* * *}$ & $0.362^{* * *}$ & $0.301^{* * *}$ & $0.380 * * *$ \\
\hline & $(0.00212)$ & $(0.00222)$ & $(0.00237)$ & $(0.00230)$ & $(0.00240)$ & $(0.00254)$ \\
\hline \multirow[t]{2}{*}{ log Destination Tech. } & $0.0198^{* * *}$ & $0.0182^{* * *}$ & $0.0218^{* * *}$ & $0.0228^{* * *}$ & $0.0207^{* * *}$ & $0.0245^{* * *}$ \\
\hline & $(0.000149)$ & $(0.000158)$ & $(0.000167)$ & $(0.000161)$ & $(0.000168)$ & $(0.000177)$ \\
\hline \multirow[t]{2}{*}{ log Distance } & $-0.276^{* * *}$ & $0.0184^{* * *}$ & $-0.163^{* * *}$ & $-0.251^{* * *}$ & -0.000442 & $-0.152^{* * *}$ \\
\hline & $(0.00118)$ & $(0.00153)$ & $(0.00192)$ & $(0.00133)$ & $(0.00177)$ & $(0.00212)$ \\
\hline \multirow[t]{2}{*}{ Border Dummy } & $1.417^{* * *}$ & $0.805^{* * *}$ & $0.656^{* * *}$ & $1.209^{* * *}$ & $0.653^{* * *}$ & $0.611^{* * *}$ \\
\hline & $(0.00393)$ & $(0.00475)$ & $(0.00617)$ & $(0.00462)$ & $(0.00541)$ & $(0.00680)$ \\
\hline EPO Member & $-0.743^{* * *}$ & $-0.728^{* * *}$ & $-0.917^{* * *}$ & $-0.833^{* * *}$ & $-0.783^{* * *}$ & $-0.979 * * *$ \\
\hline Dummy & $(0.00291)$ & $(0.00312)$ & $(0.00350)$ & $(0.00345)$ & $(0.00361)$ & $(0.00389)$ \\
\hline \multirow[t]{2}{*}{ Sigma } & $0.0144^{* * *}$ & $0.0155^{* * *}$ & $0.0213^{* * *}$ & $0.0186^{* * *}$ & $0.0198^{* * *}$ & $0.0143^{* * *}$ \\
\hline & $(0.00140)$ & $(0.00143)$ & $(0.00154)$ & $(0.00159)$ & $(0.00161)$ & $(0.00170)$ \\
\hline Common Language & & $0.400^{* * *}$ & $0.180^{* * *}$ & & $0.426^{* * *}$ & $0.136^{* * *}$ \\
\hline Dummy & & $(0.00302)$ & $(0.00353)$ & & $(0.00342)$ & $(0.00385)$ \\
\hline Trade Agreement & & $0.796^{* * *}$ & $0.354^{* * *}$ & & $0.628^{* * *}$ & $0.380^{* * *}$ \\
\hline Dummy & & $(0.00321)$ & $(0.00409)$ & & $(0.00385)$ & $(0.00453)$ \\
\hline Differentiated Good & & $0.0693^{* * *}$ & $0.0737^{* * *}$ & & $0.0878^{* * *}$ & $0.123^{* * *}$ \\
\hline Dummy & & $(0.00585)$ & $(0.00639)$ & & $(0.00663)$ & $(0.00711)$ \\
\hline Reference Priced & & $-0.0242^{* * *}$ & $-0.0659^{* * *}$ & & $0.0355^{* * *}$ & $0.0288^{* * *}$ \\
\hline Dummy & & $(0.00541)$ & $(0.00593)$ & & $(0.00614)$ & $(0.00660)$ \\
\hline Organized Exchange & Dropped & Dropped & Dropped & Dropped & Dropped & Dropped \\
\hline \multicolumn{7}{|l|}{ Dummy } \\
\hline \multirow[t]{2}{*}{$\log$ Origin GDP } & & & $0.473^{* * *}$ & & & $0.412^{* * *}$ \\
\hline & & & $(0.000881)$ & & & $(0.000992)$ \\
\hline \multirow[t]{2}{*}{ log Origin Tech. } & & & $0.0670^{* * *}$ & & & $0.0675^{* * *}$ \\
\hline & & & $(0.000174)$ & & & $(0.000201)$ \\
\hline 2-digit Industry & Yes & Yes & Yes & Yes & Yes & Yes \\
\hline \multicolumn{7}{|l|}{ Fixed Effects } \\
\hline Time Fixed & Yes & Yes & Yes & Yes & Yes & Yes \\
\hline \multicolumn{7}{|l|}{ Effects } \\
\hline \multirow[t]{2}{*}{ Constant } & $-16.62^{* * *}$ & $-20.04^{* * *}$ & $-33.16^{* * *}$ & $-19.68^{* * *}$ & $-22.08 * * *$ & $-36.95^{* * *}$ \\
\hline & $(0.0311)$ & $(0.0335)$ & $(0.0460)$ & $(0.0472)$ & $(0.0441)$ & $(0.0645)$ \\
\hline Observations & 18709711 & 18546196 & 17138773 & 11634504 & 11522934 & 10981974 \\
\hline Pseudo R-squared & 0.301 & 0.286 & 0.402 & 0.336 & 0.321 & 0.400 \\
\hline
\end{tabular}

Robust standard errors are in parentheses.

Regression disturbance terms are clustered at the destination country level.

${ }^{*} p<0.05, * * p<0.01, * * * p<0.001$

The results confirm all of the predictions of the model. Namely that larger, more technologically sophis- 
ticated markets attract a greater proportion of patents. At the industry-level, we also see that products that are more substitutable are also more likely to be patented. In addition, other trade factors play a significant role in the proportion of patents mainly due to increased trade flows. I find that both distance, border dummies, language and trade agreements play a significant role in determining which patents get sent where. The regression is also quite accurate given the low resolution of the industry fixed effects and lack of country, country-industry pair or country-pair fixed effects. To get a sense of the actual impact of these coefficients, I calculate the marginal effect of each variable (i.e. elasticity) based on the coefficients from column (3) and column (6). These results are found below:

\begin{tabular}{lcc} 
Table 6: Estimated Elasticities of Coefficients & \\
\hline \hline Explanatory & Unbalanced & Balanced \\
Variable & $(1)$ & $(2)$ \\
\hline Destination GDP & $0.0368^{* * *}$ & $0.0510^{* * *}$ \\
& 0.000043 & 0.0000593 \\
Destination IPR & $0.0102^{* * *}$ & $0.0106^{* * *}$ \\
& 0.000069527 & 0.000070878 \\
Destination Technology & $0.0010^{* * *}$ & $0.0015^{* * *}$ \\
& 0.00000794 & 0.0000111 \\
Distance & $-0.007^{* * *}$ & $-0.009^{* * *}$ \\
& 0.0000912 & 0.0001328 \\
EPO Dummy & $-0.043^{* * *}$ & $-0.061^{* * *}$ \\
Language & 0.0001623 & 0.0002351 \\
Trade Agreement & $0.0085^{* * *}$ & $0.0084^{* * *}$ \\
Sigma & 0.0001676 & 0.0002403 \\
& $0.0168^{* * *}$ & $0.0237^{* * *}$ \\
\hline \hline
\end{tabular}

Robust standard errors are in parentheses.

Regression disturbance terms are clustered at the destination country level $* p<0.05,{ }^{* *} p<0.01, * * * p<0.001$

The elasticities indicate that patenting is most sensitive to the destination country's GDP. This may be due to a variety of reasons, the most obvious being the larger market size to sell the goods and increased competition. Unfortunately, it is not possible to measure the number of competitors each firm faces in other countries, but it seems clear that competition, whether domestic or foreign, plays a significant role in determining patenting outcomes. Among the continuous variables, IP protection appears to be the next most sensitive factor determining international patenting, which is unsurprising. The technology level is also significant, but less sensitive. Among the dummy variables, being a member of the EPO will lead to a 4-6\% 
drop in the proportion of patents entering individual member countries. Signing a trade agreement leads to a $1-2 \%$ increase in the exchange of patents between the agreeing countries. Finally, sharing a language only leads to a modest increase in patent exchange. To map the full effect, I include charts showing the predicted patenting propensity based on log destination GDP, log technology, IPR and log sigma.
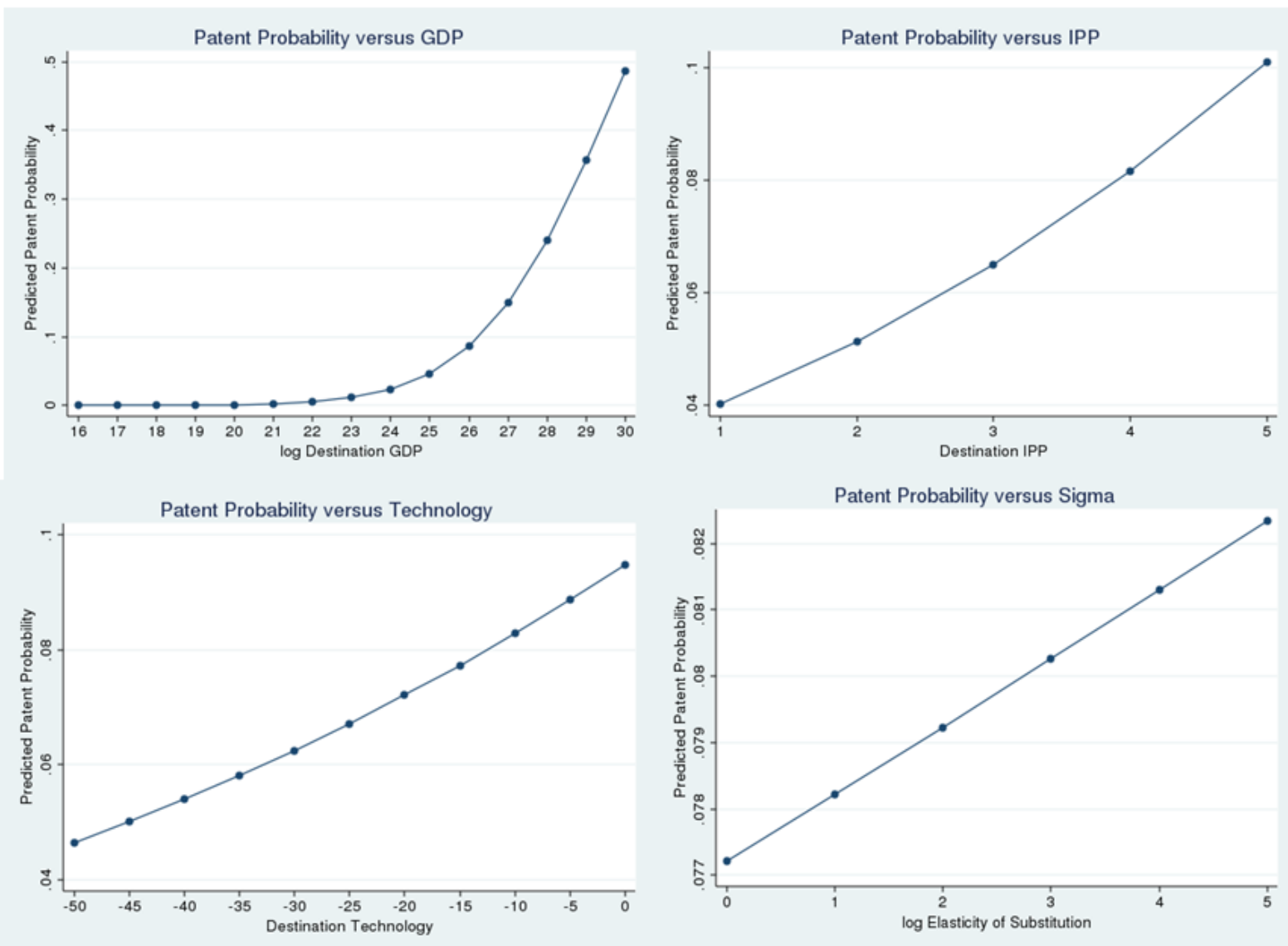

Figure 10: Patenting Propensity

Figure 10 shows several interesting properties. Namely, destination GDP appears to not influence patenting until the destination GDP becomes sufficiently large. From that point, it appears that the destination country becomes a "core" country where patenting essentially becomes automatic. As for the other variables, the benefits to increasing them appear to be linear. Technology appears to plays a large role, with the most technologically sophisticated countries attaining a nearly $10 \%$ increase in patenting over the least technologically sophisticated. Destination IPR also plays an important role with the highest levels of intellectual 
property protection leading to a $10 \%$ increase in patenting. Finally, we see that the elasticity of substitution also is important, but has only minor effects.

As an additional exercise, I also wanted to map whether the conditions to patent abroad have changed or become more/less sensitive over time. To do this study, I run the same logit regression for each individual year from 1996 to 2005 and then chart the values of the coefficients for each variable below. Note that all of the variables are significant at the $0.1 \%$ confidence and the flat red line in the charts is the coefficient from column (3) in Table 5.

Destination GDP Coefficients, 1996-2005

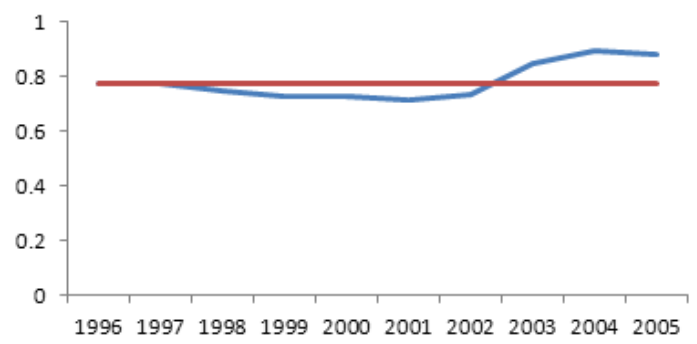

Destination Tech. Coefficients, 1996-2005

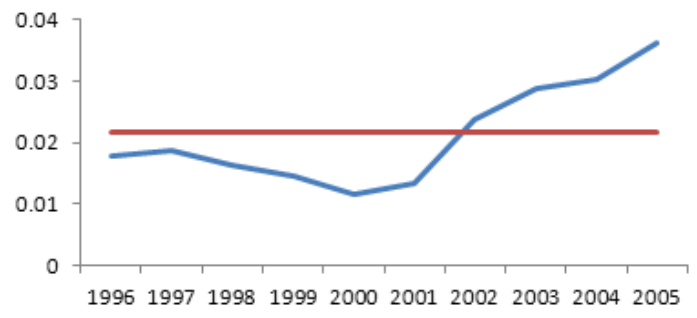

Border Coefficients, 1996-2005

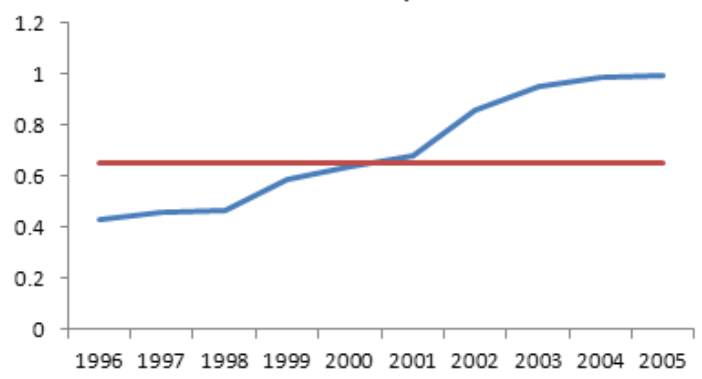

Destination IPP Coefficients, 1996-2005

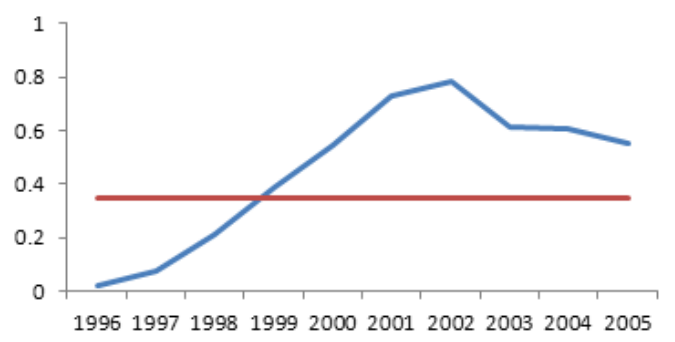

Distance Coefficients, 1996-2005

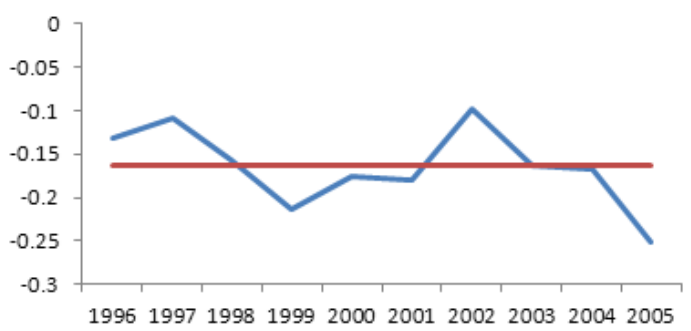

Language Coefficients, 1996-2005

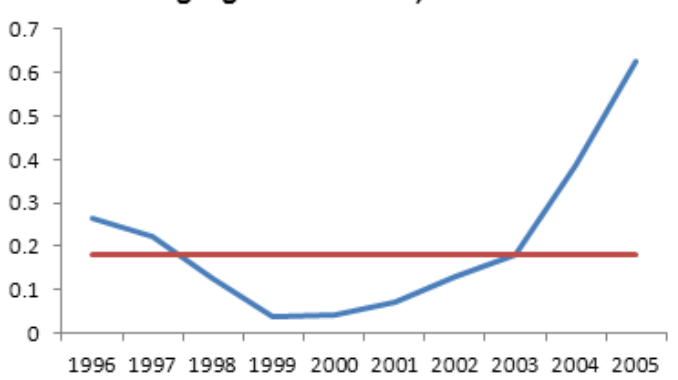

Figure 11: Change in Coefficients over Time

The figure indicates that the destination country's IPR measure has taken an increasingly significant role in determining patenting outcomes beginning in 1999. This implies that companies are placing more and more 
importance on the intellectual property environment of a country, while still considering other factors more or less equally. Firms are more sensitive to the IP environment which means that as countries continue to improve their IPR, then we can be reasonably confident that firms from abroad will respond positively to these improvements. On the other hand, this also implies that countries that do not make the necessary improvements can expect to see fewer and fewer patents coming their way. Technological sophistication is also playing a more important role in determining patent flows. This may be a result of the desire for increased specialization. Finally, we see that border effects and language are also becoming somewhat more relevant in today's decision to patent.

\section{Conclusion}

The goal of this paper was to better understand how multinational firms decide whether and where to seek international patent protection. These decisions are shown to have critical implications for future investment, technology diffusion and economic growth, especially for developing countries who linger outside of the patent core. This paper proposes a new type of patenting decision model that borrows elements from the heterogeneous firm trade literature and can explain significant portions of spatial patenting patterns. The model explains why countries with higher levels of technology, better patent protection and more competition are able to solicit a greater number of patents. Using a generalized version of the patenting cutoff condition, I was able to compile IPR measures for almost 30 countries of various size and income over the ten-year period from 1996-2005 using patent family data and parameter estimates from previous trade models. These IPR measures take into account the actual patent flows to each country and when matched with alternative IPR indices, strongly suggest that there is not enough patent transfer taking place, which has important implications for Article 66.2 of the TRIPs agreement.

In addition, a logit regression testing the model's properties was run using country-industry patent flows occurring between the years 1996 to 2005. The estimation confirmed the model's predictions and also provided measures for the effect of each factor on a firm's propensity to patent. Firms consider the destination's market size to be the most important factor in determining whether or not to patent, followed by the country's IP environment and technological sophistication. In terms of policy, countries with the highest level of IPR can expect to attract $10 \%$ more patents than countries who do not value IP protection. Also, of interest, it appears that the destination country's IP environment is taking an increasingly important role 
in the decision to patent abroad, which implies that as countries continue to make improvements to their IP, firms are responding accordingly.

Although the model is described in full detail, several properties of the model remain unknown. One of the more interesting aspects that has yet to be explored are the welfare effects that arise from strengthening IPRs. Increased patent protection has been shown to increase the expected profits of innovating firms, but it is not clear whether that leads to more potential entrants/varieties or what the negative effects it has on consumers who must now pay higher markups. It may be the case that the gain in welfare from the availability of new varieties outweighs the welfare loss from higher prices, which is the argument put forth by rich countries in the TRIPS agreement. Analyzing this question will help in addressing whether Article 66.2 of the TRIPS agreement has had a positive or negative impact on developing countries who were forced to make improvements to their IPRs. Another related property to explore would be the impact of trade liberalization on patenting and welfare.

Other possible extensions to the model include allowing foreign entry of rivals and incorporating an innovation component. Under the current framework, all of the potential rivals are local. Given the assumptions on the productivity constraints of rivals, it makes little sense to include foreign rivals since they would have to pay for the additional trade costs, making it unlikely that they would ever become the low-cost rival. On the other hand, by making the number of potential rivals in each country proportional to market size, I leave open the possibility of foreign entry (similarly based on market size). Including foreign rivals would add robustness to the model since in many cases, multinational firms use patents as a deterrence and blocking device for outside competitors trying to gain access to a particular market. Second, although the model includes innovating firms, there is no decision variable for innovation. It is certainly possible to include this component, since the profits for innovating firms are well-defined and it would be interesting to see how rivals, patent protection and country variables impact this decision.

Outside of the theoretical extensions, many empirical extensions can be made. A more robust parameterization of the model may be possible using the country-industry level data. For instance, it may be possible to obtain country technology measures for different industries using the patent data, which would then be used to analyze the effects of investments in key industries and follow these investments over time. This would be a similar-type analysis to Shikher (2004), but while using patent data instead of trade and expand into more industries and include more developing countries. 
Modeling international patent flows is an important step in understanding the process of technology diffusion and the transfer of knowledge abroad. The policy implications provided by the model are suggestive and rather broad. Improving country-level technological ability is rather difficult and requires a multi-pronged approach with investments in many different sectors of the economy. Similarly, improvement in the competitive environment also requires coordination among a number of different sectors. Many developing countries have improved upon their intellectual property protection and this has shown to be increasingly effective, but it is not clear whether firms will continue to respond positively to these changes. There also appears to be a trade-off between intellectual property rights and developing industrial capacity (Falvey et al. (2006)). Nevertheless, the model provides a testable framework for international patenting decisions and may lead to more policy in the future for developing more effective IPR regimes. 


\section{References}

Archaya, Ram and Wolfgang Keller, "Technology Transfer Through Imports," Canadian Journal of Economics, November 2009, 42 (4), 1411-1448.

Atkeson, Andrew and Ariel Burstein, "Pricing-to-Market, Trade Costs, and International Relative Prices," American Economic Review, December 2008, 98 (5), 1998-2031.

Branstetter, Lee, "Is Foreign Direct Investment a Channel of Knowledge Spillovers? Evidence from Japan's FDI in the United States," Journal of International Economics, March 2006, 68 (2), 325-344.

_, Raymond Fisman, and C. Fritz Foley, "Do Stronger Intellectual Property Rights Increase International Technology Transfer? Empirical Evidence from U.S. Firm-Level Panel Data," Quarterly Journal of Economics, February 2006, 121 (1), 321-349.

Broda, Christian and David Weinstein, "Globalization and the Gains from Variety," Quarterly Journal of Economics, May 2006, 121 (2), 541-585.

Cohen, Wesley, Richard Nelson, and John Walsh, "Protecting Their Intellectual Assets: Appropriability Conditions and Why U.S. Manufacturing Firms Patent (or Not)," NBER Working Paper No. w7552, February 2000.

Costinot, Arnaud, Dave Donaldson, and Ivana Komunjer, "What Goods do Countries Trade? A Quantitative Explortaion of Ricardo's Ideas," Review of Economic Studies, 2012, 79 (2), 581-608.

de Blas, Beatriz and Katheryn Russ, "Understanding Markups in the Open Economy under Bertrand Competition," Working Paper, September 2011.

Dernis, Helene, Dominique Guellec, and Bruno Van Pottelsberghe de la Potterie, "Using Patent Counts for Cross-Country Comparisons of Technology Output," STI Review No. 27, OECD, 2001.

Eaton, Jonathan and Samual Kortum, "Technology in the Global Economy: A Framework for Quantitative Analysis," Manuscript, University of Minnesota, 2009.

_ and Samuel Kortum, "Trade in Ideas: Patenting and Productivity in the OECD," Journal of International Economics, May 1996, 40 (3-4), 251-278.

_ and _ , "Trade in Ideas: Patenting and Productivity in the OECD," Journal of International Economics, May 1996, 40 (3-4), 251-278. 
_ and _, "Technology, Geography, and Trade," Econometrica, September 2002, 70 (5), 1741-1779.

Ethier, Wilfred and James Markusen, "Multinational Firms, Technology Diffusion and Trade," Journal of International Economics, August 1996, 41 (1-2), 1-28.

Falvey, Rod, Neil Foster, and David Greenaway, "Intellectual Property Rights and Economic Growth," Review of Development Economics, November 2006, 10 (4), 700-719.

Fieler, Ana Cecilia, "Non-Homotheticity and Bilateral Trade: Evidence and a Quantitative Explanation," Working Paper, 2007.

Grossman, Gene and Elhanan Helpman, Innovation and Growth in the Global Economy, Cambridge, Mass.: MIT Press, 1991.

Helpman, Elhanan, Marc Melitz, and Stephen Yeaple, "Export Versus FDI with Heterogeneous Firms," American Economic Review, March 2004, 94 (1), 300-316.

Horstmann, Ignatius, Glenn MacDonald, and Alan Slivinski, "Patents As Information Transfer Mechanisms: To Patent or (Maybe) Not to Patent," Journal of Political Economy, October 1985, 93 (5), $837-858$.

Keller, Wolfgang, "International Technology Diffusion," Journal of Economic Literature, September 2004, $42(3), 752-782$.

Livne, Oren, "A Cost Conscious Approach to Patent Application Filings," Les Nouvelles, June 2006, 41 (2), 115-119.

Luttmer, Erzo, "Selection, Growth, and the Size Distribution of Firms," Quarterly Journal of Economics, 2007, 122 (3), 1103-1144.

Lybbert, Travis and Nikolas Zolas, "Data Mining and Probabilistic Matching Methods for Linking International Patent Classifications to Trade and Industry Classifications," forthcoming in Research Policy, 2014.

Nadarajah, Saralees, "Distribution Properties and Estimation of the Ratio of Independent Weibull Random Variables," Asta-advances in Statistical Analysis, 2010, 94 (2), 231-246.

Owen-Smith, Jason and Walter Powell, "To Patent or Not: Faculty Decisions and Institutional Success at Technology Transfer," Journal of Technology Transfer, 2001, 26 (1-2), 99-114. 
Park, Walter, "International Patent Protection: 1960-2005," Research Policy, May 2008, 37 (4), 761-766.

Prudnikov, A.P., Y.A. Brychkov, and O.I. Marichev, Integrals and Series, Vols. 1, 2 and 3, Amsterdam: Gordon and Breach Science Publishers, 1986.

Rauch, James, "Network Versus Markets in International Trade," Journal of International Economics, June 1999, 48 (1), 7-35.

Rinne, Horst, The Weibull Distribution: A Handbook, New York: Chapman \& Hall/CRC, 2009.

Schneiderman, Anne, "Filing International Patent Applications Under the Patent Cooperation Treaty (PCT): Strategies for Delaying Costs and Maximizing the Value of Your Intellectual Property Worldwide," in "Intellectual Property Management In Health and Agricultural Innovation: A Handbook of Best Practices," MIHR: Oxford, U.K. and PIPRA: Davis, U.S.A, 2007.

Shikher, Serge, "Putting Industries into the Eaton-Kortum Model," Suffolk University Manuscript, July 2004. 


\section{A Mathematical Appendix}

\section{A.1 Proofs}

Result 1: The number of rivals $r_{i j}(\omega)$ and their average efficiency increases as the state of technology $T_{j}$ increases.

Proof: First, I show that the number of rivals increases as with $T_{j}$ :

$$
\frac{\partial r_{i j}}{\partial T_{j}}=w_{j}^{-\theta} Y_{j}^{R}\left[\left(\tilde{c}_{i j}^{R}\right)^{\theta^{k}}-\left(c_{i j}^{I}\right)^{\theta}\right] e^{-T_{j} w_{j}^{-\theta}\left[\left(\tilde{c}_{i j}^{R}\right)^{\theta}-\left(c_{i j}^{I}\right)^{\theta}\right]}>0
$$

Next, I show that the productivity of the rivals increases with technology $T_{j}$. I do this by showing that for any given cost parameter $c_{i j}^{I} \leq c^{\prime}$, the probability that $c$ is less than or equal to $c^{\prime}$ is increasing with $T_{j}$ :

$$
\frac{\partial \operatorname{Pr}\left[c \leq c^{\prime} \mid c_{i j}^{I}\right]}{\partial T_{j}}=w_{j}^{-\theta}\left[\left(\tilde{c}_{i j}^{R}\right)^{\theta}-\left(c_{i j}^{I}\right)^{\theta}\right] e^{-T_{j}^{k} w_{j}^{-\theta}\left[\left(\tilde{c}_{i j}^{R}\right)^{\theta}-\left(c_{i j}^{I}\right)^{\theta}\right]}>0
$$

Result 2: The number of rivals $r_{i j}(\omega)$ increases with the cutoff condition of rival entry $\tilde{c}_{i j}^{R}$. Proof:

$$
\frac{\partial r_{i} j}{\partial \tilde{c}_{i j}^{R}}=Y_{j}^{R} T_{j} w_{j}^{-\theta} \theta\left(\tilde{c}_{i j}^{R}\right)^{\theta-1} e^{-T_{j} w_{j}^{-\theta}\left[\left(\tilde{c}_{i j}^{R}\right)^{\theta}-\left(c_{i j}^{I}\right)^{\theta}\right]}>0
$$

Result 3: The number of rivals $r_{i j}(\omega)$ and their productivity increases with the productivity parameter of the innovating firm.

Proof: I start by first showing that the number of rivals increases as the cost parameter for the innovating firm declines:

$$
\frac{\partial r_{i j}}{\partial c_{i j}^{I}}=-Y_{j}^{R} T_{j} w_{j}^{-\theta} \theta\left(c_{i j}^{I}\right)^{\theta-1} e^{-T_{j} w_{j}^{-\theta}\left[\left(\tilde{c}_{i j}^{R}\right)^{\theta}-\left(c_{i j}^{I}\right)^{\theta}\right]}<0
$$

So that as $c_{i j}^{I}$ declines (i.e. the innovating firm is more productive), the number of rivals increases. the Next, I show that for any given productivity $c_{i j}^{I} \leq c^{\prime}$, the probability that $c$ is less than or equal to $c^{\prime}$ is decreasing with $c_{i j}^{I}$, meaning that as $c_{i j}^{I}$ decreases, it is more likely for $c$ to be less than $c^{\prime}$ :

$$
\frac{\partial \operatorname{Pr}\left[z \geq z^{\prime} \mid z^{I}\right]}{\partial z^{I}}=-T_{j} w_{j}^{-\theta} \theta\left(c_{i j}^{I}\right)^{\theta-1} e^{-T_{j} w_{j}^{-\theta}\left[\left(\tilde{c}_{i j}^{R}\right)^{\theta}-\left(c_{i j}^{I}\right)^{\theta}\right]}<0
$$


So that the distribution of rival costs when the innovating firm has very low $c_{i j}^{I}$, first-order stochastically dominates the distribution with higher $c_{i j}^{I}$ implying that the expected value of the rivals' productivity is increasing in $z_{i j}^{I}$.

Result 4: The probability the innovating firm charges the CES markup in country $j$ is decreasing in contestability $r_{i j}$.

Proof:

$$
\frac{\partial \phi_{i j}}{\partial r_{i j}}=\frac{-T_{i} T_{j}^{\theta}\left(w_{i} d_{i j} w_{j}\right)^{\theta}\left(\bar{m}^{\theta}-1\right)}{\left[r_{i j} T_{j}\left(w_{i} d_{i j}\right)^{\theta}\left(\bar{m}^{\theta}-1\right)+T_{i} w_{j}^{\theta}\right]^{2}}<0
$$

Result 5: The probability the innovating firm charges the CES markup in country $j$ increases as the cutoff condition for rival entry decreases and decreases as the innovating firm becomes more productive (lower costs).

Proof:

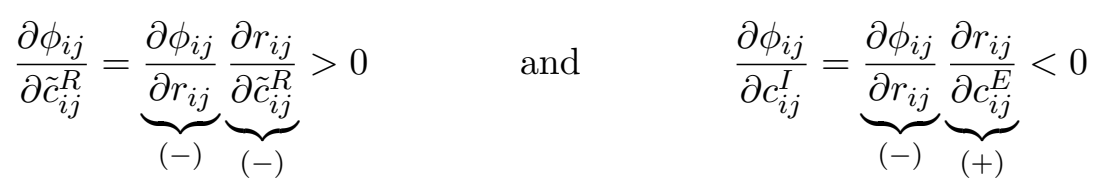

Result 6: The innovating firm's expected profit $\mathrm{E}\left[\pi_{i j}^{I}(\omega)\right]$ is decreasing in contestability $r_{i j}$. Proof:

$$
\frac{\partial \pi_{i j}^{I}}{\partial r_{i j}}=\left(\frac{c_{i j}^{I}}{P_{j}}\right)^{1-\sigma} \alpha_{j} w_{j} L j[\underbrace{\frac{\partial \phi_{i j}}{\partial r_{i j}}}_{(-)} \frac{(\sigma-1)^{\sigma-1}}{\sigma^{\sigma}}+\underbrace{\frac{\partial\left(1-\phi_{i j}\right)}{\partial r_{i j}}}_{(+)} \underbrace{\frac{\partial\left(\left(\bar{m}_{i j}^{B}\right)^{1-\sigma}\left(1-\left(\bar{m}_{i j}^{B}\right)^{-1}\right)\right)}{\partial r_{i j}}}_{? ?}]
$$

So that the sign is going to depend on how the expected markup under Bertrand competition $\bar{m}_{i j}^{B}$ changes with $r_{i j}$. I show that for any given markup $1 \leq m^{\prime} \leq \bar{m}$, the probability that $m$ is great than or equal to 
$m^{\prime}$ decreases as $r_{i j}$ increases.

$$
\frac{\partial \operatorname{Pr}\left[m \geq m^{\prime}\right]}{\partial r_{i j}}=\frac{-T_{i} T_{j}^{\theta}\left(w_{i} d_{i j} w_{j}\right)^{\theta}\left(\left(m^{\prime}\right)^{\theta}-1\right)}{\left[r_{i j} T_{j}\left(w_{i} d_{i j}\right)^{\theta}\left(\left(m^{\prime}\right)^{\theta}-1\right)+T_{i} w_{j}^{\theta}\right]^{2}}<0
$$

This implies that markup $m_{i j}^{B}$ with a small amount of rivals $r_{i j}$ first-order stochastically dominates $m_{i j}$ with a high number of rivals $r_{i j}$, so that $\frac{\partial\left(\left(\bar{m}_{i j}^{B}\right)^{1-\sigma}\left(1-\left(\bar{m}_{i j}^{B}\right)^{-1}\right)\right)}{\partial r_{i j}}<0$, which means that $\frac{\partial \pi_{i j}^{I}}{\partial r_{i j}}<0$, thus completing the proof.

Result 7: The price of variety $\omega$ charged to consumers in country $j$ is decreasing in contestability $r_{i j}$ From the price definition (Equation 9), I first compute the moment $1-\sigma$ for the expected marginal costs:

$$
\mathrm{E}\left[\left(c_{i j}^{I}\right)^{1-\sigma}\right]=\int_{0}^{\infty}\left(c_{i j}^{I}\right)^{1-\sigma} g_{i j}\left(c_{i j}^{I}\right) d c_{i j}^{I}=\left(T_{i}\left(w_{i} d_{i j}\right)^{-\theta}\right)^{\frac{\sigma-1}{\theta}} \Gamma\left(\frac{1+\theta-\sigma}{\theta}\right)
$$

$\mathrm{And}^{25}$

$\mathrm{E}\left[\left(c_{i j}^{R *}\right)^{1-\sigma}\right]=\int_{c_{i j}^{I}}^{\infty}\left(c_{i j}^{R *}\right)^{1-\sigma} g_{i j}^{R *}\left(c_{i j}^{R *}\right) d c_{i j}^{R *}=e^{r_{i j} \frac{T_{j}}{T_{i}}\left(\frac{w_{i} d_{i j}}{w_{j}}\right)^{\theta}}\left(r_{i j} T_{j} w_{j}^{-\theta}\right)^{\frac{\sigma-1}{\theta}} \Gamma\left(\frac{1+\theta-\sigma}{\theta}, r_{i j} \frac{T_{j}}{T_{i}}\left(\frac{w_{i} d_{i j}}{w_{j}}\right)^{\theta}\right)$

From this, the proof is relatively straightforward.

Proof:

$$
\frac{\partial p_{i j}}{\partial r_{i j}}=(\underbrace{\frac{\partial \phi_{i j}}{\partial r_{i j}}}_{(-)} \bar{m}+\underbrace{\frac{\partial\left(1-\phi_{i j}\right)}{\partial r_{i j}}}_{(-)} \underbrace{\frac{\partial \bar{m}_{i j}^{B}}{\partial r_{i j}}}_{(-)}) c_{i j}^{I}<0
$$

${ }^{25}$ Note that after integrating $\mathrm{E}\left[\left(c_{i j}^{R *}\right)^{1-\sigma}\right]$, I have

$$
\mathrm{E}\left[\left(c_{i j}^{R *}\right)^{1-\sigma}\right]=\int_{c_{i j}^{I}}^{\infty}\left(c_{i j}^{R *}\right)^{1-\sigma} g_{i j}^{R *}\left(c_{i j}^{R *}\right) d c_{i j}^{R *}=e^{r_{i j} T_{j} w_{j}^{-\theta} \mathrm{E}\left[\left(c_{i j}^{I}\right)^{\theta}\right]}\left(r_{i j} T_{j} w_{j}^{-\theta}\right)^{\frac{\sigma-1}{\theta}} \Gamma\left(\frac{1+\theta-\sigma}{\theta}, r_{i j} T_{j} w_{j}^{-\theta} \mathrm{E}\left[\left(c_{i j}^{I}\right)^{\theta}\right]\right)
$$

Next, I substitute the expected value $\mathrm{E}\left[\left(c_{i j}^{I}\right)^{\theta}\right]$ which is

to complete the formula.

$$
\mathrm{E}\left[\left(c_{i j}^{I}\right)^{\theta}\right]=\int_{0}^{\infty}\left(c_{i j}^{I}\right)^{\theta} g_{i j}\left(c_{i j}^{I}\right) d c_{i j}^{I}=\frac{\left(w_{i} d_{i j}\right)^{\theta}}{T_{i}}
$$




\section{A.2 Derivation of Markup Distribution}

To derive the distribution of the markup $m_{i j}$ it is necessary to look at the distribution of the ratio $c_{i j}^{R *} / c_{i j}^{I}$. To calculate this, I use the methodology in Nadarajah (2010) who use the following Lemma from Prudnikov et al. (1986)

Lemma 1 (Equation (2.3.1.13), Prudnikov et al. (1986), Vol. 1) For $\gamma>1, a>0$ and $s>0$

$$
\int_{0}^{\infty} x^{\gamma-1} e^{\left(-s x-a x^{k}\right)} d x=I(\gamma, a, k, s)
$$

Where

$$
I(\gamma, a, k, s)= \begin{cases}\sum_{j=0}^{q-1} \frac{(-a)^{n}}{j ! s^{\gamma+k n}} \Gamma(\gamma+k j)_{p+1} F_{q}\left(1, \Delta(\rho, \gamma+k j) ; \Delta(q, 1+j) ;(-1)^{q} z\right) & 0<k<1 \\ \sum_{h=0}^{p-1} \frac{(-s)^{h}}{k h ! a(\gamma+h) / k} \Gamma\left(\frac{\gamma+h}{k}\right)_{q+1} F_{p}\left(1, \Delta\left(q, \frac{\gamma+h}{k}\right) ; \Delta(p, 1+h) ; \frac{(-1)^{p}}{z}\right) & k>1 \\ \frac{\Gamma(\gamma)}{(a+s)^{\gamma}} & k=1\end{cases}
$$

Where $k=p / q$ and $z=\left(p^{p} a^{q}\right) /\left(s^{p} q^{q}\right)$ and $\Delta(v, a)=(a / v,(a+1) / v, \ldots,(a+v-1) / v)$.

Given the following distributions for $c_{i j}^{I}$ and $c_{i j}^{R *}$

$$
G_{i j}^{I}\left(c_{i j}^{I}\right)=1-e^{-T_{i}\left(w_{i} d_{i j}\right)^{-\theta}\left(c_{i j}^{I}\right)^{\theta}} \quad \text { and } \quad G_{i j}^{R *}\left(c_{i j}^{R *}\right)=1-e^{-r_{j} T_{j} w_{j}^{-\theta}\left(\left(c_{i j}^{R *}\right)^{\theta}-\left(c_{i j}^{I}\right)^{\theta}\right)}
$$


The CDF of $m_{i j}=c_{i j}^{R *} / c_{i j}^{I}$ is:

$$
\begin{aligned}
& H\left(m_{i j}\right)=\int_{0}^{\infty} G_{i j}^{R *}\left(c_{i j}^{I} m_{i j}\right) g_{i j}^{I}\left(c_{i j}^{I}\right) d c_{i j}^{I} \\
& =\int_{0}^{\infty}\left[1-e^{-r_{j} T_{j} w_{j}^{-\theta}\left(\left(c_{i j}^{I} m_{i j}\right)^{\theta}-\left(c_{i j}^{I}\right)^{\theta}\right)}\right] \theta T_{i}\left(w_{i} d_{i j}\right)^{-\theta}\left(c_{i j}^{I}\right)^{\theta-1} e^{-T_{i}\left(w_{i} d_{i j}\right)^{-\theta}\left(c_{i j}^{I}\right)^{\theta}} d c_{i j}^{I} \\
& =\theta T_{i}\left(w_{i} d_{i j}\right)^{-\theta} \int_{0}^{\infty}\left(c_{i j}^{I}\right)^{\theta-1}\left[1-e^{-r_{j} T_{j} w_{j}^{-\theta}\left(m_{i j}^{\theta}-1\right)\left(c_{i j}^{I}\right)^{\theta}}\right] e^{-T_{i}\left(w_{i} d_{i j}\right)^{-\theta}\left(c_{i j}^{I}\right)^{\theta}} d c_{i j}^{I} \\
& =\int_{0}^{\infty} g^{I}\left(c_{i j}^{I}\right) d c_{i j}^{I}-\theta T_{i}\left(w_{i} d_{i j}\right)^{-\theta} \int_{0}^{\infty}\left(c_{i j}^{I}\right)^{\theta-1} e^{-r_{j} T_{j} w_{j}^{-\theta}\left(m_{i j}^{\theta}-1\right)\left(c_{i j}^{I}\right)^{\theta}} e^{-T_{i}\left(w_{i} d_{i j}\right)^{-\theta}\left(c_{i j}^{I}\right)^{\theta}} d c_{i j}^{I} \\
& =1-\theta T_{i}\left(w_{i} d_{i j}\right)^{-\theta} \int_{0}^{\infty}\left(c_{i j}^{I}\right)^{\theta-1} e^{-r_{j} T_{j} w_{j}^{-\theta}\left(m_{i j}^{\theta}-1\right)\left(c_{i j}^{I}\right)^{\theta}} e^{-T_{i}\left(w_{i} d_{i j}\right)^{-\theta}\left(c_{i j}^{I}\right)^{\theta}} d c_{i j}^{I}
\end{aligned}
$$

I make the following substitution

$$
\begin{aligned}
x & =r_{j} T_{j} w_{j}^{-\theta}\left(m_{i j}^{\theta}-1\right)\left(c_{i j}^{I}\right)^{\theta} \\
a & =\frac{T_{i}\left(w_{i} d_{i j}\right)^{-\theta}}{r_{j} T_{j} w_{j}^{-\theta}\left(m_{i j}^{\theta}-1\right)}
\end{aligned}
$$

I can now rewrite my equation above as

$$
H\left(m_{i j}\right)=1-a \int_{0}^{\infty} e^{-x} e^{-a x} d x
$$

I can now apply Lemma 1 where $\gamma=1, k=1$ and $s=1$ so that the CDF for markup $m_{i j}$ is

$$
H\left(m_{i j}\right)=1-a I(1, a, 1,1)=1-\frac{a \Gamma(1)}{a+1}=1-\frac{a}{a+1}=\frac{1}{a+1}=1-\frac{T_{i} w_{j}^{\theta}}{r_{j} T_{j}\left(w_{i} d_{i j}\right)^{\theta}\left(m_{i j}^{\theta}-1\right)+T_{i} w_{j}^{\theta}}
$$

\section{With PDF}

$$
h\left(m_{i j}\right)=\frac{r_{j} T_{i} T_{j} \theta\left(w_{i} w_{j} d_{i j}\right)^{\theta} m_{i j}^{\theta-1}}{\left[r_{j} T_{j}\left(w_{i} d_{i j}\right)^{\theta}\left(m_{i j}^{\theta}-1\right)+T_{i} w_{j}^{\theta}\right]^{2}}
$$

